\title{
The Nature and Causes of Spontaneous Abortions with Normal Karyotypes
}

\author{
D. I. RUSHTON
}

\section{INTRODUCTION}

A review of the nature and causes of karyotypically normal spontaneous abortions presupposes that the mechanisms concerned in the loss of these conceptuses are different from those with chromosomal abnormalities. It also assumes that the mechanisms involved in their loss are understood. Neither of these assumptions has a firm scientific basis and currently neither stands up to close scrutiny.

There are no reported series of spontaneous abortions in which cytogenetic studies have been successful in every instance. There is, however, limited evidence that the biological behavior of mothers losing conceptuses where cytogenetic analysis has failed is similar to that where it has been successful (Carr et al., 1966). In those series of abortions with a known karyotype the majority of authors have not compared the morphology of those with normal chromosomes with those that were abnormal (see below). Furthermore, there is considerable variation in the classification and terminology applied to morphological descriptions, which makes direct comparisons difficult. It therefore follows that much of the data that have been published provide only a partial insight into the differences between these two groups; as a result, much of this review must be of a speculative nature.

The myth that a chromosomal abnormality per se is the direct cause of abortion is still widely believed, although it is no better founded than that which implicated morphological abnormalities as causative factors prior to the availability of techniques for chromosomal analysis. The differential survival rates of various chromosomal (J. H. Edwards et al., 1967) and morphological (Fantel et al., 1980) abnormalities are a clear indication that a simple cause and effect relation does

D. I. RUSHTON • Department of Pathology, University of Birmingham, and Birmingham Maternity Hospital, Edgbaston, Birmingham B15 2TG, England. 
not exist between these anomalies and early pregnancy wastage. The chromosomal abnormality and the expulsion of the conceptus represent but two stages in a sequence of biological events leading to reproductive wastage.

The factors that influence the outcome of any individual pregnancy with an abnormal conceptus are both numerous and ill understood, as might be anticipated in view of our limited insight into normal pregnancy, particularly where events in the first and second trimesters are concerned. The cellular events occurring prior to, during, or immediately following fertilization that lead to chromosome anomalies must be seen as the first steps in a chain of events, knowledge of many links of which is missing, which may lead to expulsion of the conceptus from the womb. The latter process is, by definition, common to all abortions, but it is not yet clear whether conceptuses with chromosomal, anatomic, or other abnormalities arrive at this final event by separate but converging routes or whether they join a final common pathway, perhaps at different points, prior to their expulsion.

One of the major reasons for the present uncertainties is the fragmented nature of current knowledge. Few women who abort have a comprehensive series of investigations performed covering all the disciplines that have been implicated clinically in early pregnancy wastage. Thus, while there is an extensive literature on the clinical, endocrinological, morphological, cytogenetic, microbiological, biochemical, and immunological aspects of abortion, there is no readily discernible pathophysiological interrelation linking all these differing approaches and data.

Early studies of spontaneous abortions were largely devoted either to the clinical problems (Goldzieher and Benigno, 1958) and possible therapeutic regimes for the prevention of loss (Shearman and Garrett, 1963) or to the morphology of the expelled products of conception (Mall and Meyer, 1921; Hertig and Sheldon, 1943). Endocrinological (Schweditsch et al., 1979; Duff et al., 1980) and cytological studies (Hassan 1965) were made in patients with a history of recurrent abortion or those threatening to abort. Their success was limited, but they did provide further basic knowledge about the biological events associated with threatened and spontaneous abortion. Cytogenetic investigations began in the early 1960s and Carr (1963) reported the first substantial series of abortions and stillbirths in which karyotyping was successful. More recently ultrasensitive endocrinological techniques (J. F. Miller et al., 1980) and ultrasonic scanning in early pregnancy (Robinson, 1975) have enabled the real rather than the apparent clinical wastage to be determined. The immunological enigma of pregnancy remains under close scrutiny, but is far from satisfactory resolution, the role of immunological factors in spontaneous abortions being unproven. Advances in our understanding of the major complications of potentially viable pregnancies, i.e., preeclamptic toxemia, fetal intrauterine growth retardation, and prematurity (Robertson, 1976; Sheppard and Bonnar, 1976; Rushton, 1981), suggest that a significant proportion of these disorders have their inception in early pregnancy, thus emphasizing that artificial temporal divisions of pregnancy have no comparable biological counter- 
parts. Thus reproductive wastage cannot, and should not, be compartmentalized by gestational age. It must be considered as a continuum beginning with fertilization and ending with the attainment of reproductive maturity of the succeeding generation (Lilienfeld and Pasamanick, 1955).

\section{MECHANISMS OF ABORTION}

Until it is clear what the processes are that lead to abortion it is difficult, if not impossible, to draw comparisons between different groups of abortions, however they may be subclassified. Early abortion, particularly when it occurs prior to a woman being aware she is pregnant, may be likened to menstruation and described as a late, frequently heavy period. Midtrimester abortions have many similarities to premature labor and early stillbirths. Indeed, the different definitions of viability throughout the world mean that a viable birth as legally defined in one country may be classed as a spontaneous abortion in another. The factors involved in triggering the onset and the progression of normal or premature labor are little understood and the relative importance of maternal and fetal factors is disputed (Liggins et al., 1977). Many stillbirths remain unexplained after comprehensive autopsies, placental examination, and a detailed review of the clinical data. Since the vast majority of spontaneous abortions, particularly those that are macerated, receive neither detailed autopsies nor placental examination and the clinical histories are often minimal, it is not surprising that the causes and mechanisms of early pregnancy wastage are largely unknown.

The clinical abortion rate, i.e., the rate among women who are aware they are pregnant, is generally accepted to be between 10 and 20\% (Pettersson, 1968) although ultrasonic and endocrinological techniques suggest at least twice as many pregnancies are aborted (J. F. Miller et al., 1980).

There are many classifications of aborted material, the majority being based on the presence or absence of an embryo or fetus and the normality or otherwise of that embryo or fetus. The author currently uses a classification based on the morphology and pathology of the placenta (Rushton, 1978) rather than of the embryo or fetus, although abnormalities of the latter are recorded. Three major groups are recognized:

I. Blighted ova, with a mean ovulation age of 9.4 weeks.

II. Macerated embryos or fetuses, the diagnosis of maceration being apparent from the histological examination of the placenta, with a mean ovulation age of 14.1 weeks.

III. Fresh embryos or fetuses, also recognizable from the placental histology, with a mean ovulation age of 18.6 weeks.

In an unselected population approximately two-thirds of cases will fall into groups I and II, the remainder into group III or an unclassifiable category. It is 
not unreasonable to expect that the majority of very early abortions detected by ultrasound or endocrinologically will fall into group I. If the real abortion rate is assumed to be approximately $40 \%$ (and this may be an underestimate), $85 \%$ of all losses will fall into groups I and II, i.e., blighted ova or intrauterine embryonic or fetal deaths. These two groups have at least one major physiological and morphological factor in common, an absent intravillous circulation. In the blighted ova group this is due to failure of villous vascularization, whereas in the macerated group it is due to cessation following death of the embryo or fetus. It has been suggested (Rushton, 1984) that the absence of an embryonic or fetal circulation within the placenta ultimately affects trophoblastic function and thus the maintenance of a normal hormonal milieu, the decline of which eventually leads to expulsion of the conceptus. Thus, in these two groups the development and survival of the embryo is the crucial factor in allowing pregnancy to continue, i.e., the conceptus determines the outcome of pregnancy. This argument inevitably poses further questions: Why was the ovum blighted? What teratogenic conditions, if any, led to the failure of embryonic development and how do they act? What are the causes of embryonic and fetal death in utero? Chromosomal abnormalities may make a major contribution, but they by no means answer these questions completely. Few chromosomal abnormalities are totally incompatible with survival in utero until the fetus is considered to be viable. Equally, many of the anatomical malformations found in the embryo or fetus are also present in viable births. Thus the relation of these abnormalities to embryonic or fetal death remains enigmatic.

Where then are we most likely to find the highest proportion of chromosomally normal conceptuses? Simple logic would suggest the blighted ova would be most likely to have chromosomal anomalies, while fresh midtrimester losses would be the least likely. The macerated group is less clear cut and might form an intermediate group.

Several large series of unselected spontaneous abortions in which chromosome banding techniques were used have been reported (Lauritsen et al., 1976; Takahara et al., 1977; Hassold et al., 1978; Kajii et al., 1980). Karyotyping was successful in $57-90 \%$ of cases and chromosomal abnormalities were found in 30.5$54.9 \%$, the study reporting the highest rate only including specimens up to 18 weeks of gestation, whereas all but one of the remaining included tissues of up to 28 weeks of gestation.

\section{INCIDENCE OF CHROMOSOMALLY NORMAL ABORTUSES}

Comparative and concurrent studies of morphology and karyotype are less numerous than those of either karyotype or morphology alone, but show a consistent relation between these two approaches. 
Singh and Carr $(1967,1968)$, analyzing a series of spontaneous abortions of known chromosomal constitution, found that approximately half the intact empty sacs and ruptured sacs had a chromosomal abnormality, as did those conceptuses with an anatomic abnormality. However, chromosomal abnormalities were only present in $6 \%$ of anatomically normal specimens. Of the chromosomally normal embryos, $17 \%$ were shown to be anatomically abnormal. Poland (1968) examined 125 specimens of embryos and fetuses and found morphological abnormalities in 54 instances. She noted that three-quarters of these abnormalities were known to occur in stillbirths or newborn infants. The morphological abnormality rate correlated with the size and gestational age; thus, among specimens between 0 and 35 days of age $87 \%$ were abnormal; the corresponding figures for $35-55,56-90$, and $91-154$ days were 45,42 , and $16.6 \%$ respectively. Geisler and Kleinebrecht (1978) found chromosomal anomalies in $57 \%$ of intact but empty sacs, and in approximately $40 \%$ of specimens consisting of fragmented dead villi and membranes, open sacs with embryos, and intact sacs with embryos; while $30 \%$ of open sacs without an embryo were abnormal. None of the normal fetuses had a karyotypic abnormality, although only 13 cases were included in the series. Kajii et al. (1980), comparing anatomical and karyotypic abnormalities in 639 spontaneous abortions with a crown-rump length of less than $100 \mathrm{~mm}$, received 565 unselected cases, of which 402 were successfully karyotyped; $53.5 \%$ were abnormal. Among the total, 339 specimens were considered incomplete with no embryo or fetus, 110 were anatomically normal, and 190 abnormal. Poland et al. (1981) in a study of 1961 women and their conceptuses examined 2020 products of conception. Among these were 1126 embryos, 813 fetuses, 31 moles, and 50 unclassified specimens. Morphological abnormalities were present in $84 \%$ of the embryos and $25 \%$ of the fetuses. Among the embryos, one-quarter of the anatomically normal specimens had a chromosomal abnormality, while almost $60 \%$ of those showing growth disorganization (intact sacs with no embryos, amorphous embryos, grossly disorganized embryos up to $10 \mathrm{~mm}$ in length, and embryos showing a major distortion of body shape) had a karyotypic abnormality. Two-thirds of the embryos with other morphological abnormalities had a chromosomal abnormality. Among the fetuses, $2 \%$ of the normal and $22 \%$ of the abnormal had a chromosomal anomaly.

Inevitably there are variations in the detailed analyses of these data, but the study of Warburton et al. (1980) in New York may be considered representative of the overall pattern reported in the literature.

These authors examined 1605 specimens and were successful in karyotyping $59.1 \%$ with an overall chromosomal abnormality rate of $32.1 \%$. The proportion of specimens showing karyotypic abnormalities varied with the morphology of the products of conception. Thus the incidence of chromosomal abnormalities was as follows:

Ruptured sacs with no cord stump $\quad 56.1 \%$

Disorganized fetuses $53.9 \%$ 
Intact empty sacs

Ruptured sacs with a cord stump

Anatomically normal macerated fetuses

Abnormal fetuses

Anatomically normal nonmacerated fetuses
$50.0 \%$

$41.4 \%$

$26.8 \%$

$24.0 \%$

$4.6 \%$

Thus the majority of clinically apparent spontaneous abortions had a normal karyotype, and even in the most grossly abnormal conceptuses where an embryo has failed to develop, only just over half the specimens had chromosomal abnormalities. It follows that in the case of complete but empty sacs and ruptured sacs with no cord stumps (blighted ova) the presence of a chromosomal abnormality per se does not result in abortion, but rather that the disturbance of development and function associated with the formation of a blighted ovum is of prime importance. In both the chromosomally abnormal and normal conceptuses there is an inherent defect that eventually leads to abortion. There is limited evidence that in a few blighted ova abnormal hormonal synthesis or multiple enzyme deficiencies in the placental tissue may be responsible (Edlow et al., 1971; Weiner and Friedlander, 1971). Several other groups of morphological abnormalities also show chromosomal anomalies in approximately half the karyotyped specimens. It is only when fetuses with identifiable anatomical abnormalities, anatomically normal macerated fetuses, and normal nonmacerated fetuses are considered that there is a significant excess of chromosomally normal conceptuses, i.e., 76, 73.2, and $95.4 \%$, respectively.

It is also worthy of note that, excluding the 0- to 7-week gestation specimens, the incidence of chromosomal anomalies falls progressively as the duration of pregnancy increases; thus $49.2 \%$ were abnormal between 8 and 11 weeks, $39.1 \%$ between 12 and 15 weeks, $18.5 \%$ between 16 and 19 weeks, and $11.1 \%$ over 20 weeks. Other studies have suggested a progressive fall from the time of fertilization. Mikamo (1970) found 75, 50, 5.3, 6.3, and $0 \%$ at 4, 5-8, 9-12, 13-16, and 17-28 weeks, respectively; and in the perinatal period $9.5 \%$ of macerated stillbirths, $3.5 \%$ of nonmacerated stillbirths, and $5.1 \%$ of liveborn perinatal deaths had chromosomal abnormalities (Angell et al., 1984).

From these data and other studies of chromosomal abnormalities in spontaneous abortions it is clear that if there are differences in the nature and mechanism of abortion among those with a normal karyotype, the groups that merit further study are anatomically normal macerated fetuses, fetuses with identifiable anatomical abnormalities, and in particular normal nonmacerated fetuses.

It would seem probable that the blighted ova, be they empty sacs or ruptured sacs with or without a cord root, behave similarly whether or not they have a chromosomal abnormality. It might be argued that the anatomically normal macerated fetus with or without a chromosomal abnormality aborts via a similar pathophysiological pathway that may be related to cessation of the fetal circulation 
and that the high proportion of karyotypically normal conceptuses in this group is simply a reflection of the earlier elimination of the majority of the chromosomally abnormal group. However, the cause of death of these fetuses is unknown and it cannot be supposed that the chromosomal abnormality necessarily leads to their death.

It is at this stage that our concepts become clouded by the isolationist approach of most studies of spontaneous abortions. Clinical, endocrinological, epidemiological, immunological, and therapeutic studies of aborting women have ignored the products of conception from the women under investigation, while morphological examination of the conceptus has been carried out in isolation from the clinical data. The embryological approach to aborted embryos and fetuses has deterred routine pathological examination of these specimens, and the aborted placenta is frequently simply taken as an indicator of pregnancy. It is because of this divergent approach together with a widespread belief in some quarters that little or nothing is to be learnt from examining the products of conception that will be of benefit to the patient that the majority of clinical studies must be interpreted with caution, particularly when they purport to show a relation between maternal and environmental factors and spontaneous abortion (Knill-Jones et al., 1975; Nixon et al., 1979; Harlap and Shiono, 1980; Harlap et al., 1980; Kline et al., 1980; Hemminki et al., 1982). In no other area of medicine is the specimen obtained from the patient ignored to the extent that it is from aborting women. It is inconceivable that any study of malignant disease would be conducted without accurate pathological identification of the lesion, yet such an approach is the rule rather than the exception in early pregnancy wastage.

It may be concluded from the foregoing discussion that the only significant difference between abortuses with a normal karyotype and those with an abnormal karyotype is that, by definition, there are no normal conceptuses in the latter category. Few chromosomal abnormalities may be identified morphologically in spontaneous abortions with a reasonable degree of accuracy in the absence of cytogenetic studies. Many of the more gross disturbances of development appear to occur with equal frequencies in both chromosomally normal and abnormal conceptuses. This is almost certainly a reflection of the limited responses open to the fertilized ovum when influenced by a teratogenic insult, be it chromosomal, genetic, or environmental. The majority of fetuses with identifiable anatomical abnormalities and the majority of fetal deaths have a normal karyotype, as do almost all anatomically normal fresh fetuses. If the complexities of teratogenesis are excluded from this discussion, as they must be, then we are left with three major problems:

1. What are the causes of fetal death in utero in the absence of both chromosomal and morphological abnormalities? 
2. What are the mechanisms involved in the premature expulsion of apparently normal fresh fetuses and placentas from the uterus?

3. Are any of the morphological abnormalities found in karyotypically normal abortions responsible for pregnancy wastage?

In an attempt to answer these questions it is necessary to consider both clinical aspects of spontaneous abortion and the pathology of the conceptus. The former may suggest possible avenues of research, while the latter may provide clues to both the causes and mechanisms of spontaneous abortion. In considering the morphology it is of paramount importance to include the placenta as well as the embryo or fetus since it alone is in direct contact with the maternal organism and is essential for the establishment of a normal physiological environment for both the embryo (or fetus) and its host.

\section{CLINICALLY IMPLICATED CAUSES OF SPONTANEOUS ABORTION}

The vast literature devoted to spontaneous abortion emphasizes both our ignorance and interest in the problem. Much of it is contradictory and confusing. Since, as has been emphasized, few such studies concern themselves with the morphology of the conceptus, it is not impossible that many of the clinically important etiological factors act independently of the nature of the conceptus. Theoretically they might act as cofactors; thus it has been suggested that spina bifida might result from an $\mathrm{X}$-linked defect in an unproven selective abortion mechanism (Burns and Gibbons, 1978). Similarly it was proposed that, since thalidomide had a mild immunosuppressive function, the high incidence of limb malformations was due to failure of rejection of these abnormal fetuses (Hellmann, 1966). Some suspected teratogens, particularly hormones (Matsunaga and Shiota, 1979; Schardein, 1980), may not only influence embryonic development, but also alter the uterine environment. It has also been suggested that certain factors might delay the expulsion of an abnormal conceptus; thus, long-acting progestagens may cause missed abortion (Piver et al., 1967). Indeed, the latter possibility formed the rationale behind the use of hormones in the treatment of habitual and threatened abortions (Goldzieher, 1964).

The temporal compartmentalization of pregnancy has tended to obscure the fact that virtually all the etiological considerations familiar to obstetricians as being responsible for both perinatal morbidity and mortality may also influence early pregnancy, while some may decrease fertility. Although the clinical presentation of retroplacental hemorrhage or placental abruption in a potentially viable pregnancy is widely recognized, the same is not true in early pregnancy, although there is no logical reason to expect that these lesions should be confined to a par- 
ticular period of gestation. The same is true of premature rupture of the membranes and infection. It is pertinent, however, that while better obstetric care has had a dramatic effect on perinatal mortality, the clinically apparent spontaneous abortion rate does not appear to have declined significantly this century, if criminal or procured abortions are excluded.

This must, in part, reflect the very high incidence of abnormalities among early pregnancy losses that are not susceptible to prevention, but it may also be partly explained by the fact that better antenatal care does not begin until after most spontaneous abortions have occurred. The advent of preconception clinics (Anonymous, 1981) and care may eventually reduce the incidence of spontaneous abortions, particularly if the early promise of vitamin supplementation in reducing neural tube defects is confirmed (Anonymous, 1982) and other beneficial preventative measures are discovered. Initially it is possible preconceptional care may have its greatest impact in the prevention of the loss of morphologically normal conceptuses. However, 35 years ago (Colvin et al., 1950) only $3.9 \%$ of a series of 1570 untreated cases of threatened abortion were considered on morphological criteria to be salvageable and there is little evidence to suggest this proportion has increased in recent years either as a result of new therapeutic tools or as a result of an alteration in the abnormalities found in unselected series of spontaneous abortions.

It is clearly impossible to discuss all the factors that influence the outcome of any individual pregnancy and the clinical discussion will therefore be limited to some of the currently topical subjects.

Kissane (1981) in a review of the mechanisms involved in reproductive failure particularly as they apply to couples suffering repeated losses considered four major mechanisms that operated in early reproductive wastage:

1. Failure of the zygote to divide and implant.

2. Major chromosomal abnormalities.

3. Infection.

4. Immunological rejection.

To those the following might be added:

5. Morphological abnormalities (if it is accepted that chromosomal abnormalities per se cause abortion).

6. Abnormalities of the uterine environment and of uterine function.

7. Endocrinological disorders.

8. Maternal disease.

9. Environmental factors.

Failure of the zygote to divide and implant will be unnoticed unless it is recurrent, and will likely lead to attendance at an infertility clinic (Block 1978; Ahmed and Klopper, 1984). Major chromosomal anomalies are specifically 
excluded from this review. Morphological abnormalities, like the chromosomal abnormalities, do not usually provide an explanation for spontaneous abortion, and the curious variation in the prenatal survival of specific malformations cannot be explained on morphological grounds alone. Thus embryos or fetuses with certain limb abnormalities in which the morphological disturbance appears to be relatively minor have a proportionally higher prenatal mortality than fetuses with anencephaly (Nishimura et al., 1966, 1968). Indeed, if fetal death is of major importance in triggering the pathophysiological mechanisms leading to spontaneous abortion, there are few simple malformations that might, in themselves, result in demise of the embryo or fetus. It must therefore follow that malformations either reflect but one of several manifestations of the effect of an abortifacient agent on the conceptus, others possibly affecting its physiological and metabolic functions, or are not related to the loss of the conceptus, being a coincidental finding. In that there are clear indications of a selective process of elimination of abnormal conceptuses, whether they have anatomical or chromosomal abnormalities, the former is clearly a more acceptable hypothesis.

\subsection{Infection}

The role of infection as a cause of spontaneous abortion is controversial. The conceptus may become infected by one of two major routes, either transplacentally following hematogenous spread from the pregnant woman or as the result of an ascending infection from her lower genital tract. Many viral infections, such as rubella, cytomegalovirus, and coxsackie virus, are transmitted by the hematogenous route, as are malaria, toxoplasmosis, syphilis, and in some instances listeriosis and herpes simplex. The majority of bacterial infections, some viral infections, e.g., herpes simplex, and fungal infections, e.g., candidiasis, spread by the ascending route either directly or indirectly by establishing a focus of infection in the decidua that spreads to involve the membranes (Blanc, 1981). It is now clear that ascending infection may occur in the presence of intact membranes (Bobitt and Ledger, 1977; Naeye and Peters, 1978; J. M. Miller et al., 1980; Evaldson et al., 1982; Desa and Trevenen, 1984). Indeed, such infections may be responsible for rupture of the membranes. Infections of the conceptus in early pregnancy may result in malformation, embryonic or fetal death, rupture of the membranes, and secondary infection of the amniotic cavity and fetus after membrane rupture. Again in those instances where the conceptus dies the mechanism of abortion may be similar to that in deaths from noninfective causes. However, it must be emphasized that there is no biological reason why a chromosomally or anatomically abnormal conceptus should not acquire an infection and it therefore follows that the demonstration of an infection does not exclude either of these abnormalities nor does it substantiate the case for the infection being the cause of these abnormalities. Indeed, the almost universal finding of inflammatory changes in the 
decidua of spontaneous abortions led earlier workers to conclude that endometritis was the major cause of early pregnancy wastage (Mall and Meyer, 1921).

Infection has long been recognized as a major cause of abortion (Hafez, 1967) and teratogenesis (WHO, 1977) in animals, but its importance in humans has probably been underestimated. The number of organisms incriminated continues to increase, partly as a result of changes in bacterial taxonomy, partly because of more sophisticated techniques for isolation of organisms, particularly anaerobes, and partly because of a growing awareness of the importance of infection in pregnancy wastage.

Some of the organisms implicated are listed in Table I. Many of the bacteria are, not surprisingly, normal commensal organisms found in the vagina or on the perineum of the pregnant woman. Some may be considered to be of low pathogenicity in adults. By no means have all these organisms been specifically identi-

Table I. Infections That May Be Associated with Spontaneous Abortion $^{a}$

\begin{tabular}{|c|c|c|}
\hline Organisms & Hematogenous spread & Ascending infection \\
\hline Viruses & $\begin{array}{l}\text { Cytomegalovirus } \\
\text { Rubella } \\
\text { Rubeola } \\
\text { Hepatitis } \\
\text { Mumps } \\
\text { Herpes simplex } \\
\text { Poliomyelitis } \\
\text { Varicella zoster } \\
\text { Variola alastrim } \\
\text { Vaccinia } \\
\text { Coxsackie } \\
\text { Influenza }\end{array}$ & $\begin{array}{l}\text { Herpes simplex } \\
\text { Cytomegalovirus }\end{array}$ \\
\hline Bacteria & $\begin{array}{l}\text { Enteric bacteria } \\
\text { Gram-positive cocci } \\
\text { Listeria } \\
\text { Campylobacter }\end{array}$ & $\begin{array}{l}\text { Vaginal and perineal commensals } \\
\text { Listeria } \\
\text { Campylobacter } \\
\text { Brucella }\end{array}$ \\
\hline Other & $\begin{array}{l}\text { Treponema pallidum } \\
\text { Vibrio fetus } \\
\text { Leptospira } \\
\text { Mycoplasmas } \\
\text { Rickettsiae } \\
\text { Toxoplasma } \\
\text { Plasmodia } \\
\text { Trypanosoma } \\
\text { Schistosoma } \\
\text { Chlamydia }\end{array}$ & $\begin{array}{l}\text { Candida albicans } \\
\text { Aspergillus } \\
\text { Actinomyces } \\
\text { Mycoplasmas } \\
\text { Trichomonas } \\
\text { Vibrio fetus } \\
\text { Chlamydia }\end{array}$ \\
\hline
\end{tabular}

${ }^{a}$ Blanc (1981), Rosenberg et al. (1981). 
fied as causes of abortion, but they have been identified in or isolated from products of conception at some stage in pregnancy.

\subsubsection{Ascending Infection}

The interrelation between infection of the amniotic cavity and rupture of the membranes remains contentious. It is often assumed that such infections occur as the result of rupture of the membranes, the organisms gaining access through the defect. It has also been clearly demonstrated that the longer the duration of rupture of the membranes, particularly if it exceeds $48 \mathrm{~h}$, the greater the likelihood of amniotic infection, although these studies were concerned with pregnancy after the attainment of fetal viability (Benirschke and Driscoll, 1967). In the presence of normal quantities of liquor amnionii most pregnant women are aware of membrane rupture in the last trimester, but in early pregnancy the exact time of rupture is often unknown or uncertain since the volume of amniotic fluid lost may be so small or the leak so slow as to escape the notice of the woman. However, chorioamnionitis is common among spontaneous abortions, particularly among those resulting in anatomically normal midtrimester losses, i.e., those in which chromosome abnormalities are least common. In the author's experience at least onequarter of fresh, anatomically normal abortions are affected, whereas only onehalf that proportion of macerated specimens show evidence of membranitis (Rushton, 1984). In a significant proportion there is also evidence of fetal infection, suggesting prolonged rupture of the membranes (H. Elbana and D. I. Rushton, unpublished data). Since rupture of the membranes does not inevitably lead to the onset of uterine activity and labor, particularly in early pregnancy, where prolonged periods of leakage of amniotic fluid may result in oligohydramnios, fetal moulding, and pulmonary hypoplasia (Perlman et al., 1976), as well as amnion nodosum, additional factors must be sought to explain the loss of these conceptuses. Among these will be uterine factors such as cervical incompetence (see below), but infection may play a significant role. It has been shown that there is a significantly higher level of prostaglandin $\mathrm{E}$ in amniotic fluid following spontaneous abortion (Karim and Devlin, 1967; Karim and Hillier, 1970) and in the decidua of spontaneous abortions than in induced abortions (Jaschevatzky et al., 1983), although it is not yet clear whether this increase is a primary event or secondary to decidual or fetal lesions. However, it is known that bacterial contamination of amniotic fluid can increase phospholipase $\mathrm{A}_{2}$ activity (Bejar et al., 1981), which in turn leads to the production of prostaglandins, which may then play a role in the initiation of premature labor. Spread of the inflammatory process within the decidua may also result in necrosis, hemorrhage, and placental separation, which might lead either to embryonic or fetal death and missed abortion or to more rapid expulsion in the face of extensive retroplacental hemorrhage and placental separation. There are therefore reasonable grounds for supposing that infection from the lower genital tract may account for a significant proportion 
of anatomically normal, predominantly midtrimester spontaneous abortions. Pathologically such cases are typified by the loss of the normal translucency of the placental membranes, which may become totally opaque, varying from yellowishwhite to red-brown in color. In some instances focal lesions may be identified in the membranes and umbilical cord, typically in candida infections (Blanc, 1981; Rushton, 1982). Microscopy reveals an acute, often necrotizing chorioamnionitis, funiculitis (inflammation of the umbilical cord), and less often fetal skin and pulmonary inflammation. The last is more likely to occur if infection is established in the presence of intact membranes or fetal survival is prolonged after rupture and ascending infection.

\subsubsection{Hematogenous Infection}

Unlike most ascending infections, blood-borne infections of the conceptus are not associated with abnormalities of the placental membranes. Embryonic or fetal infection is usually disseminated, although the liver is generally most severely affected, since this is the first organ encountered by infected blood returning from the placenta. The characteristic placental lesion is villitis, inflammation of the villous stroma, often with accumulation of polymorphs in the intervillous space and local fibrin deposition. These changes are usually nonspecific and unless a particular infection is suspected prior to fixation of the tissues the exact nature remains enigmatic in the absence of a clear clinical history of maternal infection.

In some cases diagnosis may be possible by microscopy, e.g., listeriosis, tuberculosis, toxoplasmosis, cytomegalovirus, and malaria, but some infections leave minimal evidence of placental involvement, e.g., rubella and coxsackie viruses. Recurrent abortion associated with villitis of undetermined origin has been reported (Russell et al., 1980). Among the viruses reputed to cause abortion are mumps, rubeola, cytomegalovirus, variola, vaccinia, poliomyelitis, and rubella, while influenza, herpes simplex, varicella zoster, coxsackie, and hepatitis B virus remain unproven causes (Rosenberg et al., 1981). Some of these viruses may produce severe maternal illness and their exact role in spontaneous abortion is uncertain.

Influenzal infection graphically illustrates this problem. Viremia is extremely rare in human influenza (Khakpour et al., 1969) and thus direct infection of the conceptus is unlikely. It has been demonstrated that the virus will grow in endometrium (Rosztoczy et al., 1975), so that the possibility of an ascending infection cannot be entirely excluded. It is known that spontaneous abortions, stillbirths, perinatal deaths, and congenital malformations may increase in the wake of an influenza epidemic (South, 1972; Rushton et al., 1983). Experimental studies in animals have also shown a nonspecific increase in resorption and stillbirths when the pregnant animals contracted influenza. Artificial viremia in late pregnancy in the same species is associated with endometritis, placentitis, fetal death, and resorption (Rushton et al., 1983). However, it is likely that the increased repro- 
ductive wastage associated with human influenza epidemics is not due to direct infection of the conceptus but follows the systemic disturbance in the pregnant woman. It is also possible that therapeutic measures used to treat influenza might be important.

It is therefore probable that most spontaneous abortions associated with hematogenous infections occur as the result of fetal or embryonic death. A recent prospective study of cytomegalovirus (CMV) infection in pregnancy (Griffiths and Baboonian, 1984) demonstrated a $15.4 \%$ fetal loss in women with specific IgM antibodies, compared with only $2.15 \%$ in controls. These authors emphasized that these early losses were not due to direct infection of the conceptus. However, infection of the endometrium may play a role in the loss of some abortions associated with maternal CMV infection (Dehner and Askin, 1975). It is also worthy of note that even in the face of two rubella epidemics during the period of study twice as many mothers contracted CMV infection as rubella. Thus, like influenza, the role of $\mathrm{CMV}$ in abortion is not clear and the mechanisms concerned in the loss of the conceptus remain obscure.

It is impossible to discuss the role of every individual organism incriminated as a putative cause of spontaneous abortion. There are many approaches to the identification of potential infective causes of abortion and both direct and indirect techniques may be employed. An example of the latter is a study of cervical and serum IgA and serum IgG antibodies to Chlamydia trachomatis and herpes simplex virus (Gronroos et al., 1983), which demonstrated no relation between the former and spontaneous abortion, while there was limited evidence of an association with herpes simplex virus, although this did not apply to pregnancies resulting in the loss of a blighted ovum. Thus, if herpes simplex virus is a cause of abortion, the mechanism may be allied to that of ascending bacterial infections following membrane rupture.

Finally it must be emphasized that not all pregnant women have an equal risk of infection and that some groups are particularly susceptible, suggesting that improved medical facilities might reduce the early losses due to infection.

Susceptible women include those of low socioeconomic status (Naeye and Blanc, 1970), those in certain racial groups (Appelbaum et al., 1980), those that are poorly nourished (Naeye et al., 1973), those practicing sexual intercourse during pregnancy (Naeye, 1980), those with poor personal hygiene (Blanc, 1981), and those with diabetes mellitus (Daria-Haust, 1981). The role of cervical incompetence will be discussed below, but clearly a closed cervical canal will offer greater resistance to ascending infection than will one that is partly dilated.

\subsection{Immunological Factors and Spontaneous Abortion}

If the exact role of infection as a cause of spontaneous abortion is uncertain, then the role of immunological factors is very much more obscure. Clinical folklore 
has always alleged that it is proper to explain to a woman who has recently aborted that she lost the pregnancy because her body rejected the conceptus because it was abnormal. This phraseology was introduced before the term rejection came to have a more scientific meaning specifically relating to an immune response to foreign tissue. It also led to the belief (erroneously, in the author's opinion) that the loss of these abnormal pregnancies was determined by the maternal organism rather than by the conceptus, as outlined above.

Since an immunological response necessitates exposure of the host to an appropriate antigen, it follows that such responses are more likely to occur in women suffering recurrent losses than in those having isolated abortions. Furthermore, if early pregnancy wastage occurs in over $40 \%$ of successful implantations, the development of an immunological mechanism to eliminate the abnormal conceptus might be anticipated to be detrimental to the reproductive efficiency of the species, since each succeeding pregnancy would enhance the immune response in a manner comparable to that known to occur with rhesus isoimmunization, unless there is an individual immune response to an unrelated antigen in each consecutive pregnancy. Taylor and Faulk (1981) hypothesized that immune incompatibility of HLA antigens between the parents may be beneficial and indeed essential to maintain the genetic heterogeneity of the human population. It therefore seems reasonable to suppose that immunological mechanisms are the cause of only a small proportion of spontaneous abortions, if they have any role in postimplantation pregnancy failures.

If immunological processes are implicated, how might they act? There are three probable mechanisms:

1. The maternal organism mounts a direct immunologic response to tissue components of the conceptus in direct contact with maternal tissues or blood.

2. Immunologically competent maternal cells enter the embryonic or fetal compartment and produce a graft-versus-host reaction.

3. Cells or possibly other antigenic material enter the maternal circulation from the conceptus, which induces an antibody response, the antibodies crossing the placenta to damage appropriate target organs in the embryo or fetus, as occurs in rhesus isoimmunization.

It is clearly beyond the bounds of this review to discuss the complexities of the immunological interrelation between the pregnant woman and her conceptus, a subject that has been covered in several monographs and reviews of the immunology of pregnancy and reproduction (R. G. Edwards et al., 1975; Scott and Jones, 1976; Stirrat, 1980; Hogarth, 1982).

The evidence available to date is contradictory. Animal studies indicate that immunological mechanisms may result in abortion (Diczfalusy, 1974), and rejec- 
tion may lead to fetal death and abortion in certain hybrid breeding experiments, e.g., sheep-goat hybrids (Hancock et al., 1968).

In humans the evidence is circumstantial, in that unequivocal evidence of immune rejection is yet to be demonstrated in spontaneous abortions. Human data are largely confined to studies of tissue incompatability between parents and between the mother and her fetus, and to the effects of sensitization of the female partner to paternal antigens.

ABO blood group incompatibility between mother and fetus was noted to be more frequent in women who abort (Allen, 1964; Takano and Miller, 1972), although these results conflicted with those of Pearse and Lau (1963). In a study of the relation of maternal and paternal $\mathrm{ABO}$ and rhesus types to fetal death Cohen and Sayre (1968) reviewed the records of 129,815 fetal deaths and 100,973 live births (a random 10\% sample) occurring in New York City between 1954 and 1959. They demonstrated that in white mothers ABO incompatibility was associated with a higher risk of fetal loss than in ABO-compatible mothers, the increase in fetal deaths occurring before 20 weeks of gestation, with no increase in deaths at over 28 weeks' gestation; whereas rhesus-negative mothers had a threefold increase in late fetal deaths, but no increase in early deaths. Fetal death was significantly more common in rhesus-negative than in rhesus-positive mothers. Lauritsen et al. (1975) found that blood group A and B abortuses were overrepresented among losses with a normal karyotype and underrepresented in those with an abnormal karyotype. They deduced that as many as $18 \%$ of spontaneous abortions might be due to ABO incompatibility. Among abortuses suspected to be due to $\mathrm{ABO}$ incompatibility they sought but failed to find any pathological evidence of rejection in the placentas. The mode of action of $\mathrm{A}$ and $\mathrm{B}$ antibodies was not clear, although it was suggested they might interfere with organogenesis. In mice maternal antibodies reduce fertility and increase fetal resorption rates (Parmiani and Della Porta, 1973), but there was no evidence of reduced fertility associated with human $\mathrm{ABO}$ incompatibility.

Taylor and Faulk (1981), Stirrat (1983), and a leading article in Lancet (Anonymous, 1983a) reviewed the evidence that supports a possible role for an 'ill-defined' immunological process in human pregnancy wastage with special reference to the role of maternal blocking antibodies. This may be summarized as follows:

1. Couples suffering recurrent abortions share more HLA antigens than would be expected by chance. This applies to the A, B, C, and DR loci.

2. In normal pregnancy many though not all women develop inhibitors of cell-mediated immunity which may be demonstrated in blood. Many women suffering recurrent abortions fail to produce these inhibitors.

3. Although transplantation antigens are absent from human villous trophoblast, there are discrete antigens in human trophoblastic membranes that 
in theory could induce an immune response between a pregnant woman and her conceptus. Nonvillous trophoblast carries HLA-A, B, and C antigens but not HLA-DR antigens (Sunderland et al., 1981a,b).

To date at least four classes of blocking antibodies have been described. These include:

1. Nonspecific T-cell inhibitors, which reduce the proliferative response to phytohemagglutinin or allogenic stimulation in the mixed lymphocyte reaction (MLR) (Griffin and Beck, 1983; Bissenden et al., 1980).

2. Auto-anti-idiotypic antibodies, which bind to maternal T-cell receptors for paternal HLA types (Suciu-Foca et al., 1983). These antibodies may be stimulated by blood transfusions and many explain why transfusion prior to renal transplantation increases allograft survival.

3. TLX antigens, which are shared by leukocytes and trophoblast, might be shared by mother and conceptus if both parents carry the appropriate genes. It has been suggested that TLX-compatible conceptuses may fail to stimulate blocking antibodies, which in turn leads to rejection of the conceptus (Taylor and Faulk, 1981; McIntyre and Faulk, 1982).

4. Noncytotoxic antibodies binding to paternal B cells (Power et al., 1983). These antibodies were not active against known HLA specificities, but familial studies suggest that they may be linked to the HLA gene complex.

The role of these blocking antibodies is uncertain, since not all women with normal pregnancies develop them and only the last has been demonstrated in the first trimester, the others appearing after the greater part of early pregnancy wastage has occurred. It is also not clear whether they are a cause or a result of abortion.

Taylor and Faulk (1981) treated three women with multiple transfusions of leukocyte-enriched plasma from a minimum of 16 erythrocyte-compatible donors. All had had three previous abortions and all three had a successful outcome to the treated pregnancy. A further patient with a bicornuate uterus that was surgically repaired after eight consecutive abortions suffered two further losses prior to treatment and had reached 28 weeks' gestation at the time these cases were reported. The authors suggested that the leukocyte transfusions would contain TLX antigens that would stimulate production of maternal blocking or other protective antibodies, which might prevent rejection of the blastocyst. Unfortunately there are no data concerning the gestation and nature of the previous abortions in these patients and it is not clear whether the mechanisms described would lead to any but very early spontaneous abortion. It is of note, however, that statistically significant reductions in the presence of all four blocking antibodies have been recorded in 
mothers suffering recurrent abortions. In late pregnancy the roles of these antibodies are uncertain, although it may be pertinent that parents with shared HLA antigens may suffer other complications of pregnancy, including unexplained recurrent abnormal pregnancies (Gerencer et al., 1978), neural tube defects (Schacter et al., 1979), and preeclamptic toxemia (Redman et al., 1978).

A difference in the response of women suffering recurrent abortions and recurrent hydatidiform moles (Takeuchi, 1980) is of considerable importance in that the former patients show a high reactivity on MLR testing, whereas the latter show low reactivity, particularly since hydatidiform moles are of androgenic origin (Kajii and Ohama, 1977) and should express only paternal antigens. Takeuchi (1983) had taken the argument further and suggested that moles are not, as is widely believed, neoplastic in nature, but represent a form of chromosomally abnormal conceptus associated with very early embryonic death. He hypothesized that in pregnancies where embryonic death occurs, the death may either be a primary event due to an inherent defect in the conceptus such as a lethal chromosomal abnormality, or a secondary event due to failure of blocking-antibody production with subsequent immunological destruction of the trophoblast and rejection of the conceptus. While this hypothesis is of interest, particularly in relation to the true nature of hydatidiform mole, there is no morphological evidence available to support these two modes of embryonic death; indeed, as has been suggested above, failure of development of an intravillous circulation may be the major factor determining embryonic survival.

Beer et al. (1981) also found hyporeactivity in MLRs in a proportion of couples suffering recurrent abortions and an above average incidence of parental HLA compatability. These authors hypothesized that there may be an unknown genetic locus linked to the HLA system and that certain HLA phenotypes may carry a unique surface glycoprotein on the trophoblast. Futher evidence of a possible role for paternal antigens is provided by women who change partners during their reproductive life span. Thus a woman may have a series of normal pregnancies with her first husband, only to suffer a series of recurrent abortions with a second husband (Javert, 1962) or vice versa. It is also of interest that the same type of behavior may occur with preeclampsia (Need, 1975; Feeney and Scott, 1980).

The role of blocking antibodies is outlined in Fig. 1. Since there appears to be a relation between blocking-antibody production and both maternopaternal and maternofetal histocompatability, there are alternative explanations of some of the phenomena purported to result from absent or deficient blocking antibodies. Thus maternofetal histocompatability, which is more likely to occur if the parents are histocompatible, might also result in the expression of lethal genes, as occurs in mice (Artzt, 1983; Awdeh et al., 1983), and cause embryonic death. It might also allow colonization of the conceptus with maternal lymphocytes and result in a graft-versus-host reaction (Kadowaki et al., 1965; Grogan et al., 1975). It it per- 


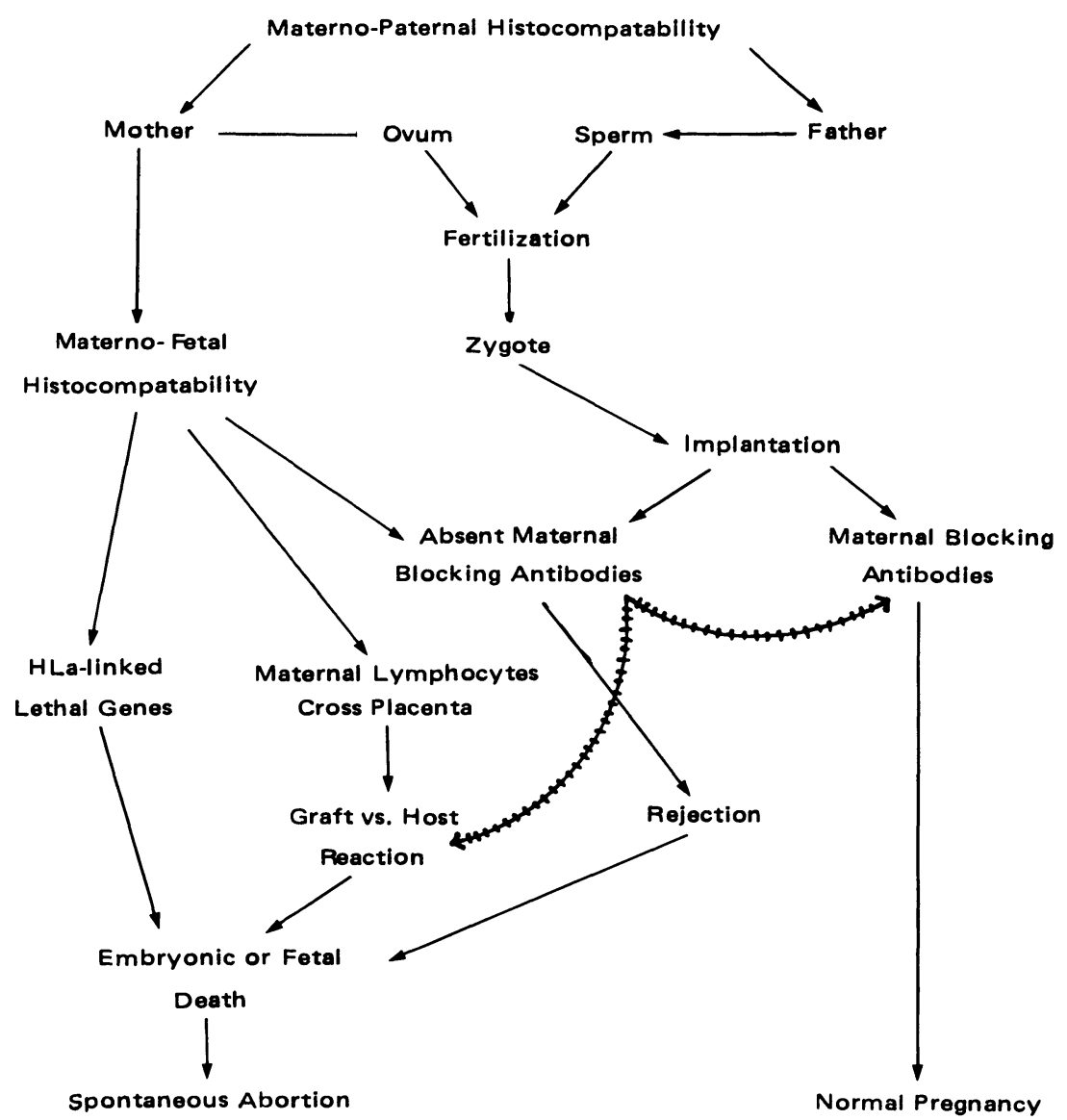

Figure 1. Interrelation of immunological and histocompatability factors and spontaneous abortion. The crossed line indicates the possible effects of maternal transfusion with a pool of mixed lymphocytes.

tinent that maternal hyperimmunization by paternal antigens, as might occur in the treatment described by Taylor and Faulk (1981), may provoke a graft-versushost reaction.

Finally differences in the sex ratio of the offspring of women who develop HLA antibodies during pregnancy have been reported (Johansen and Festenstein, 1974). More male fetuses were born to women developing HLA antibodies and the preponderance of males gradually decreased with increasing parity in some women, whereas women not developing HLA antibodies showed a progressive increase in the male-female ratio. 
It is not yet clear what the relation of these immunological data is to the nature of the conceptus. Undoubtedly such factors could act entirely independently of the nature of the products of conception. There is as yet no evidence to indicate that immunological factors play a role in spontaneous abortions associated with chromosomal abnormalities (Jenkins, 1976). Indeed, Lauritsen et al. $(1975,1976)$ demonstrated that maternofetal incompatible pregnancies and incompatible matings among $\mathrm{ABO}$ blood groups are more frequent among karyotypically normal abortuses. Furthermore, using MLRs, transformation was depressed to a greater degree when the parents had a karyotypically normal conceptus. These authors argued that these findings tend to support the view that the changes reflect the consequences of abortion rather than its cause. Jenkins (1976) has suggested that some fetuses might have abnormal immune systems, which might play a role in pregnancy wastage. The possibility that specific fetal antigens sensitize a women when she aborts cannot be discounted, since it is well established that early pregnancy losses sensitize women to rhesus factors. It has been suggested that spontaneous abortion might sensitize a woman to HLA antigens (Gelabert et al., 1981). It may therefore be pertinent that antibodies to alpha-fetoprotein may cause abortion in rabbits (Slade, 1973).

It is difficult to summarize these data, but it would appear that there are significant differences in immunological responses between women suffering and those not suffering recurrent abortions. However, women having recurrent abortions form only a very small proportion of the total aborting population and cannot be considered to be a representative population. Futhermore, the biological significance of the differences in immune response in these women is uncertain and they might all represent the effects of abortion rather than play a role in its causation.

\subsection{Morphological Abnormalities}

Evidence discussed earlier clearly emphasizes the very high incidence of morphological abnormalities among spontaneous abortions and also, in the author's opinion, confirms the view that these abnormalities per se are not the cause of abortion. Many of these malformations are associated with chromosomal anomalies. There are two major categories of anatomical abnormality:

1. The growth-disordered, stunted, amorphous, or cylindrical embryos usually only a few millimeters in length and often macerated, which under the author's classification are considered to be blighted ova. Single identifiable anatomical lesions are absent in the vast majority.

2. Embryos and fetuses with identifiable congenital abnormalities that may also be found in viable fetuses and newborn infants.

Although of interest embryologically and possibly of value in monitoring for environmental teratogens (Miller and Poland, 1970; Burdi et al., 1974; Stein et 
al., 1975; Oakley, 1975; Kline et al., 1977; Hook, 1981; Hemminki et al., $1983 a, b$ ), their major value to the clinician should be in genetic counseling (Poland and Lowry, 1974; Haxton and Bell, 1983).

The advent of ultrasound has provided data on the natural history of the abnormal conceptus prior to its expulsion from the uterus. Blighted ova are readily detected (Robinson, 1975) and there is an increasing body of evidence to indicate that in multiple pregnancies one or more of the conceptuses may be blighted (Finberg and Birnholz, 1979; Varma 1979; Uchida et al., 1983). The remaining conceptus may continue to develop normally to deliver at term. Although the zygosity of these multiple pregnancies is unknown, these cases are of interest in that they may shed further light on the immunology of abortion. In the latter part of the first trimester and in the second trimester disturbances of fetal growth may be demonstrated in a proportion of pregnancies that subsequently abort (Kurjak and Kirkinen, 1982; Mantoni and Pedersen, 1982; Pedersen, 1983). Morphological studies have also demonstrated that some fetuses show accelerated growth (Rushton, 1984). This almost certainly reflects an underestimation of the duration of pregnancy by the mother owing to bleeding at the time of the first and second missed periods and may possibly indicate a poor site of initial implantation. Growth retardation may be associated with chromosome abnormalities (Kurjak and Kirkinen, 1982), but it may also be due to uteroplacental ischemia (see below). The heterogeneity of fetal growth patterns among these abortions emphasizes their diverse etiology and the need to consider the morphology of the conceptus when investigating the nature of early human pregnancy wastage.

There is an extensive literature on the morphology and pathology of spontaneous abortion and it is not possible to consider this in depth within the constraints of this review. In addition to the series discussed above, the morphology of the embryo and fetus has been widely studied (Wingate, 1968; Tanimura, 1972; Shiota et al., 1975; Creasy and Alberman, 1976) and Poland et al. (1976) studied embryos from ectopic pregnancies and consecutive recurrent spontaneous abortions (Poland and Yuen, 1978). Placental lesions have been described by many authors (Huber et al., 1957; Sadovsky and Laufer, 1961; Eckman and Carrow, 1962; Honoré et al., 1976; Ornoy et al., 1981). The latter two series emphasized the presence of abnormal stromal cells in the villi of conceptuses with trisomy or triploidy and the high incidence of hydatidiform degeneration in blighted ova and in association with triploidy.

Ornoy et al. (1981) considered inflammatory lesions an important cause of midtrimester abortion. Less attention has been paid to lesions in the placental bed and decidua (Salhan et al., 1979), but the demonstration of uteroplacental ischemia in $5.1 \%$ of group II macerated conceptuses and $2.8 \%$ of group III fresh conceptuses and of retroplacental hemorrhage in 4.6 and $9.7 \%$ respectively, in these groups (Rushton, 1984) would suggest that uterodecidual vascular disease contributes significantly to late first and midtrimester losses. The lesions found in such 
cases in the decidua include failure of the second wave of endovascular trophoblastic invasion, arterial and arteriolar fibrinoid necrosis, and subintimal lipophages (D. I. Rushton, unpublished data). The similarity between these lesions and those described by Robertson et al. (1967) in association with hypertensive pregnancy and by Sheppard and Bonnar (1976) in association with fetal growth retardation is obvious. Since it is now generally accepted that both these complications of pregnancy are associated with disturbances in placentation that begin in the first or early second trimester, it should come as no surprise that similar lesions are to be found in some spontaneous abortions. They may indeed be responsible for some embryonic or fetal deaths as well as fetal growth retardation. Their importance lies in the fact that they occur in the absence of evidence of clinical illness in the pregnant woman and thus may go some way to explaining the divergence of opinion about their significance and specificity as they relate to preeclamptic toxemia.

It is therefore possible to conclude that morphological abnormalities of the embryo and fetus do not in themselves explain why a particular pregnancy aborts. If secondary lesions due to failure of villous vascularization or to embryonic or fetal death are excluded, then examination of the placenta, and more particularly the placental bed, may demonstrate a failure of normal vascular adaption to pregnancy, leading to placental ischemia, infarction, and separation and to fetal death or growth retardation. Such a mechanism may account for a significant proportion of midtrimester abortions and demonstrates the continuum between early failure of vascular adaption and fetal growth retardation and preeclampsia in viable pregnancies. The relation between these lesions and the karyotype of the conceptus is unknown, but it probable that the majority have a normal chromosomal constitution.

\subsection{Abnormalities of the Uterine Environment and of Uterine Function}

Abnormalities of the female genital tract have been estimated to be responsible for $15 \%$ of recurrent abortions (Glass and Golbus, 1978; Tho et al., 1979). Since they are unlikely to resolve spontaneously, they are most often associated with infertility, recurrent abortion, or premature labor (Jeffcoate and Wilson, 1956). They are probably of little significance as a cause of isolated spontaneous abortions. Certain of the malformations are surgically correctable $(\mathrm{H}$. W. Jones and Jones, 1953).

There are no systematic studies of products of conception from patients with clinically diagnosed abnormalities of the uterus, be these congenital or acquired.

There are three basic groups of lesions:

1. Those involving the body of the uterus. These include the majority of congenital abnormalities due to failure of fusion, either totally or in part, of the müllerian ducts, uterine hypoplasia, and uterine fibromyomata. 
2. Those involving the cervix and cervical canal, which present clinically as cervical incompetence.

3. Iatrogenic lesions, the most common of which is a retained intrauterine contraceptive device in the presence of a pregnancy.

Abnormalities of the body of the uterus due to failure of müllerian duct fusion may be demonstrated in $2-3 \%$ of immediate postpartum uteri (Hay, 1958; Greiss and Mauzy, 1961). There is no convincing evidence that these abnormalities are associated with an increase in first trimester losses, but between onequarter and one-half of pregnancies in these uteri may abort in the second trimester (Elias and Simpson, 1980). Abortion is usually considered to be due to the inability of the uterus to enlarge in parallel with the growing conceptus. The same mechanism may apply to the hypoplastic uterus. This is a disorder that many obstetricians describe anecdotally and is typified by a history of recurrent pregnancy loss, each succeeding pregnancy reaching a greater gestation than its predecessor. Whether such cases are due to pathological uterine hypoplasia is uncertain. Uterine fibroids may cause infertility and recurrent abortion (Elias and Simpson, 1980) and it was recently suggested that pregnancies conceived in the presence of fibroids may have an increased risk of congenital malformation (Matsunaga and Shiota, 1980).

Cervical incompetence (Lash and Lash, 1950; Gans et al., 1966) is an umbrella term for patients suffering repeated losses, usually in the second trimester in association with various degrees of painless cervical dilatation. The diagnosis is not always made on firm clinical criteria and may be made retrospectively or by exclusion. Its importance as a cause of abortion has been questioned (Cousins, 1980). Most cases are probably the result of cervical trauma, be it obstetrical or gynecological in origin (Anonymous, 1980, 1983b). It has been estimated that cervical incompetence may affect one in 125 pregnancies (Jennings, 1972). It is not clear whether the laxity of the cervix or the patent cervical canal is the more important factor, since the latter will provide a route for ascending infections to reach the decidua and membranes, as has been stressed by Russel (1979). Ultrasound examination of the cervical canal in early pregnancy may allow future diagnoses to be made with greater accuracy (Jackson et al., 1984). It would appear that some of these patients have an abnormally short cervical canal rather than a dilated canal, the short canal being more susceptible to dilatation.

Finally mention should be made of intrauterine contraceptive devices, since where they fail to prevent conception they may lead to abortion (Perlmutter, 1978) and in many instances these abortions are associated with sepsis (Eisinger, 1976; Thomas, 1975; Kim-Farley et al., 1978). The route of infection is almost invariably from below and the tail of the contraceptive device, which passes through the endocervical canal, may well provide an appropriate environment for the organism concerned to ascend into the uterine cavity. 


\subsection{Endocrinological Factors}

The establishment and normal progression of an individual pregnancy are dependent in part on the provision and maintenance of an appropriate hormonal milieu for the conceptus. Initially this is provided by the maternal pituitary-ovarian axis, which controls the maturation of the endometrium into which the blastocyst will implant. Progesterone is of key importance both in the preparation of the endometrium and the subsequent progression of the pregnancy. It is synthesized in the corpus luteum under the influence of HCG produced by the fertilized ovum until about the 8th week of pregnancy, when it is supplanted by the placenta as the principal site of steroidogenesis (Ryan, 1980). During early pregnancy 17hydroxyprogesterone is produced almost exclusively by the corpus luteum, reaching peak levels at about 6 weeks and then declining to a relatively fixed level by the 12th week (MacNaughton, 1976; Chard and Klopper, 1982). In normal pregnancies, during the period that progesterone levels remain relatively constant or decline, estradiol levels increase progressively (Aspillaga et al., 1983). Since the precursors of these hormones are maternal in origin and therefore present in excess of the needs of the conceptus, there would appear to be a reciprocal production of progesterone by trophoblast to compensate for the decline in luteal production. Concurrently trophoblastic estradiol production increases in a progressive manner.

The essential nature of progesterone in the maintenance of normal pregnancy is indicated by three observations (Ross 1979):

1. Low luteal-phase blood progesterone levels are found in some women with involuntary infertility and some that suffer recurrent spontaneous abortions.

2. Surgical excision of the corpus luteum prior to the 6th or 7 th week of pregnancy is usually followed by abortion.

3. In a few patients of the type mentioned in 1, treatment with progesterone may restore fertility or prevent abortion.

However, such patients form a very small minority of all women who abort. The role of luteal-phase inadequacy or failure (G. S. Jones, 1975) is probably insignificant as a cause of abortion and, overall, the value of the use of progestogens in the treatment of threatened or recurrent abortion remains unproven (Stirrat, 1983).

Much of the endocrinological data have accrued from women threatening to abort and in many instances the interpretation of the results as indicators of a primary endocrinological failure must be suspect in that they almost certainly reflect the effects of abnormalities, such as chromosomal anomalies, on placental function.

That serum progesterone levels are low in patients with threatened or recurrent abortions cannot be disputed (Hensleigh and Fainstat, 1979), but combined 
measurements of HCG and luteal relaxin in aborting women suggest that the failure of luteal function is secondary to inadequate placental HCG production (Quagliarello et al., 1981). HCG levels are low in patients aborting blighted ova (Schweditsch et al., 1979). Women who abort before the end of the 9th week of pregnancy have a prolonged doubling time for maternal plasma HCG levels (Chartier et al., 1979). In some instances there is evidence of abnormal hormonal synthesis in aborted placental tissue (Edlow et al., 1971; Weiner and Friedlander, 1971).

As has been suggested, many of these studies were only instituted when there was clinical evidence to suggest abortion might occur. A more recent study of the endocrinology of early pregnancy failure (Aspillaga et al., 1983) provides more meaningful data in that the authors studied the endocrine function of 14 women experiencing early pregnancy failure from the time of conception to the time of abortion. They performed serial measurements of serum estradiol, progesterone, 17-hydroxyprogesterone, prolactin, human placental lactogen (HPL), and HCG as well as monitoring the pregnancies by ultrasound. They were able to demonstrate that the serum progesterone and estradiol concentrations fell within the normal range in all patients until the 7th week of pregnancy. After the 8th week they began to decline, although remaining within the normal range. The decline appears to occur independently of the presence or absence of an embryo. They were unable to confirm the prolonged doubling times for serum HCG among their blighted ova. However, although the concentrations of progesterone remained within the normal range, the decrease in concentration distinguished those that aborted from those that did not. Even better discrimination between the two groups was apparent using estradiol, since in normal prgnancy an increase rather than a decrease would be expected. They also found that the decreasing capability of the placenta to produce steroids was independent of its ability to produce HCG and HPL.

It may be concluded from these results that trophoblast is genetically coded to produce both HCG and HPL from the time it differentiates from the other cellular components of the blastocyst and that it continues to do so whether or not embryonic differentiation occurs. Since one role of HCG is to maintain the corpus luteum so as to prevent menstruation, it might be anticipated that the ability of the trophoblast to synthesize HCG would manifest very soon after fertilization, a property confirmed by the use of the $\beta$ subunit as an ultrasensitive test of very early pregnancy (J. F. Miller et al., 1980; Ahmed and Klopper, 1984). The role of HPL is less clear, since it is known that human pregnancies may occur in the absence or near absence of the hormone as measured by current techniques (Nielsen et al., 1979; Alexander et al., 1982; Sideri et al., 1983).

Further it would appear that the trophoblast also has limited abilities to synthesize steroids independently and that in the absence of an embryo destined to survive beyond 11-12 weeks' gestation these begin to decline at about 7 weeks' 
gestation. At the same time the levels of 17-hydroxyprogesterone show an abnormal decrease, indicating a failure to maintain basal corpus luteum function (Aspillaga et al., 1983). Unfortunately, no data were given on the morphology and cytogenetics of the products of conception other than ultrasonic data showing that eight were blighted ova, while in the six with embryos or fetuses it was estimated that intrauterine death occurred between the 47 th and 81 st days of pregnancy. It is perhaps pertinent that in cases with embryos or fetuses development continued to a period when organogenesis was ending and growth and maturation were beginning. Little is known about the function of organs in the embryo or fetus at these times in gestation, but failure of the fetal endocrine system might be a factor that could explain the abnormal pattern of steroidogenesis in these pregnancies. This could indicate either a specific endocrinological failure or might reflect a general disturbance in the metabolic processes of the embryo or fetus. With the exception of one case, the duration of intrauterine death was between 12 and 38 days; thus all the fetuses would have been severely macerated, while the exception, which was dead in utero only 3 days, would have been moderately macerated. All these fetuses would fall into group II of the author's classification, in which the vast majority of fetal deaths remain unexplained.

However, although the results described above may be interpreted as supporting the concept that the endocrine abnormalities are secondary to developmental deficiencies in the conceptus, as is almost certainly true of blighted ova, the possibility that endocrine disturbances are the cause of embryonic or fetal death cannot be entirely ruled out. No examples of group III abortions were included in the study, although it might be anticipated that the fresh, apparently normal midtrimester abortions would have a normal endocrine profile during the first trimester if it is the result of local uterine factors.

Primary placental insufficiency, i.e., insufficiency due to an isolated inherent defect of the placenta, as opposed to the secondary effects of either an inadequate maternal blood supply or a failing fetal circulation, is extremely rare in viable pregnancies, but it does not follow that this is necessarily true in early pregnancy. Indeed, failure of normal trophoblastic function may be an important cause of failed implantation. Successful implantation, which is critically dependent on trophoblastic function, implies at least a degree of normality. However, syncytial hypoplasia (Aladjem, 1967, 1975) has been implicated as a cause of abortion, although there must be certain reservations about the interpretation of these data in view of the effects of circulatory abnormalities on trophoblastic growth (Rushton, 1984). Metabolic disorders are known to occur in the trophoblast of blighted ova and in later pregnancy. Placental steroid sulfatase deficiency (Harkness et al., 1983), which is associated with very low maternal estriols and fetal or infantile abnormalities, is a rare but well-recognized abnormality, which, as far as the author is aware, has not been described in early pregnancy. Failure to produce HPL, be it real or apparent, also reflects altered trophoblastic function. The role 
of these and undoubtedly other, as yet unidentified, metabolic disturbances of trophoblastic function as a cause of abortion is unknown and unexplored, but the advent of chorionic biopsy as a diagnostic technique in early pregnancy (Daker, 1983) will almost certainly reveal new examples of inherent trophoblastic defects.

In summary it seems likely that the majority of endocrine disturbances reported in association with spontaneous abortion reflect the failure of the pregnancy rather than the cause of that failure. Progesterone deficiency may play a role in some cases of infertility. G. S. Jones and Pourmand (1962) estimated that $3.5 \%$ of infertile women had a persistent luteal-phase defect, while it might be present in about one-third of women suffering habitual abortions (G. S. Jones, 1976). However, these studies are open to many criticisms, not least that the products of conception from those aborting with a supposed luteal defect were not examined. In view of the high incidence of chromosomal, anatomical, and possibly metabolic disorders in early pregnancy losses it is probable that the majority were due to inherent defects within the conceptus rather than to primary luteal failure.

Clinical evidence showing there is only a limited value in giving progesterone supplements to prevent abortion tends to confirm this hypothesis and only a very small number of infertile women, or women suffering habitual abortions, are likely to benefit from such therapy.

\subsection{Maternal Disease and Spontaneous Abortion}

Maternal ill health, as might be anticipated, has a profound effect on reproductive capability. Many serious or debilitating diseases result in infertility, while others may lead to clinically apparent spontaneous abortion. It is clearly impossible to discuss all the medical and surgical disorders that may influence the outcome of pregnancy.

Several generalizations may be made that apply to many epidemiological studies of spontaneous abortion as well as to medical and surgical disorders of pregnancy:

1. Most studies are retrospective and as such depend to a greater or lesser degree on maternal recall, which is almost certain to be affected by the outcome of pregnancy.

2. Most studies take no cognizance of the nature of the products of conception and it is therefore impossible to relate specific suspected diseases with the type of conceptus that is lost.

3. Much of the data depend on growing numbers of individual case reports or at best small series of patients, since no one center is likely to have experience with a large number of cases of any one disease, although there are notable exceptions, such as diabetes, anemia, and hemoglobinopathies as well as certain endemic infections such as malaria. 
4. It is frequently impossible to discriminate between the direct effects of the specific disease and the effects of signs such as hyperpyrexia or the effects of therapy, be this self-administered or prescribed.

The number of biological and environmental variables influencing the outcome of any individual pregnancy is so numerous that it is incumbent on those investigating the causes of pregnancy wastage either to study very large numbers of cases in order to attempt to correct for some of these variables or to demonstrate a specific mechanism that leads to abortion. It is not acceptable to implicate a disease or environmental agent epidemiologically without considering it in the context of our current knowledge of reproductive biology.

Three diseases can be used to illustrate some of these problems: diabetes mellitus, sickle cell disease, and systemic lupus erythematosus.

Diabetes mellitus is said to be associated with a marked increase in the incidence of malformations among viable births (Day and Insley, 1976; Watkins, 1982) and with certain pathological lesions in the palcenta that individually are nonspecific but together are a reasonable indicator of maternal disease (DariaHaust, 1981). However, the role of diabetes in spontaneous abortion is disputed (Goldman and Resnik, 1974; Crane and Wahl, 1981; Beral et al., 1984). Because of the high natural wastage in the absence of diabetes, a small increase due to its effect on the conceptus may easily escape detection. However, it can be hypothesized that poor diabetic control in the late first or second trimester would lead to intrauterine death and spontaneous abortion; thus diabetic mothers may show a higher proportion of group II macerated abortuses than nondiabetic controls. The detection of this difference depends on careful monitoring of the nature of the conceptus rather than the determination of the overall incidence of abortion. In this respect it is analogous to the monitoring of individual malformations that led to the identification of thalidomide as a human teratogen (Lenz and Knapp, 1962), an effect that would almost certainly have gone unnoticed if only the crude incidence of malformations was monitored. If it were shown that intrauterine death leading to abortion was more common among diabetic women, then it must follow that better diabetic control in early pregnancy might reduce this form of pregnancy wastage.

Sickle cell disease, unlike diabetes mellitus, shows marked variation in its clinical severity and in its effect on reproductive function in different parts of the world, this variation being due to a multiplicity of cofactors, such as malnutrition, infection, and coexistence of other genetic diseases, e.g., glucose-6-phosphate dehydrogenase deficiency. A recent study of sickle cell disease in pregnant women in the United Kingdom (Tuck et al., 1983) confirmed that there is a statistically significant increase of involuntary infertility, spontaneous abortion, and stillbirths among affected women. There was also an increased incidence of other complications of pregnancy that might in themselves increase pregnancy wastage, e.g., 
infections, anemia, and severe preeclampsia or eclampsia. It is again easy to hypothesize that abortions in patients with sickle cell disease might result from interference of the maternal blood supply to the placenta or within the intervillous space; but apart from the demonstration of sickle cells in the intervillous space, there is no consistent pathological evidence to support this hypothesis, although Anderson et al. (1960) demonstrated an excess of infarcts in the placentas of pregnancies with sickle cell disease.

Finally, specific mention must be made of systemic lupus erythematosus (SLE), since it is one of the few diseases associated with circulating autoantibodies that occurs in women in the reproductive age group and that may be associated with recurrent abortion. One of these antibodies, an antilipid antibody, is the socalled "lupus anticoagulant" (LA). Women with this antibody not only have bad obstetric histories, but may also suffer from intravascular thrombosis and neurological disorders (Hughes, 1983). LA occurs in other disorders, but its first association with pregnancy wastage was reported by Nilsson et al. (1975) in a woman who had three intrauterine deaths at 31,22 , and 34 weeks' gestation. A coagulation defect was diagnosed in the third pregnancy, although it was absent between the third and fourth pregnancies. In the fourth pregnancy a circulating antithromboplastin was found and a positive test obtained for antinuclear factor and leukocyte-agglutinating antibodies and lymphocytotoxic antibodies directed against her husband's cells. The authors considered the possibility that the anticoagulant might have entered the fetal bloodstream and caused intrauterine death by hemorrhage. It was also noted in the fourth pregnancy that the fetus was growth retarded and the placenta massively infarcted. Further examples of abortion associated with LA were reported by Hartikainen-Sorri and Kaila (1980) and Zulman et al. (1980). Carreras et al. (1981) suggested that LA inhibits prostacyclin formation, which may regulate the fetal circulation, and lowers uterine tone, thus reducing spontaneous contractility. Lubbe et al. (1983) suppressed maternal production of LA with prednisone and a successful pregnancy ensued in five of six mothers who had lost 13 pregnancies prior to treatment, the sixth mother suffering a further loss at 16 weeks' gestation. Of the 13 lost pregnancies, seven were over 20 weeks' gestation. In a further report, ten women with circulating LA (Lubbe et al., 1984) with 28 pregnancies prior to treatment with prednisone and aspirin had nine fetal losses under 20 weeks' gestation, eight between 21 and 28 weeks' gestation, and eight over 28 weeks' gestation. The three successful pregnancies occurred in women by their first husbands and there were no data available about the presence of LA in these instances. Among the ten women, seven were treated, with live births in six, the only failure being in a woman in whom the activated partial thromboplastin time was not suppressed to normal. In nine of the fetal deaths occurring after 20 weeks of gestation the placentas showed infarction, while five also showed intervillous thrombosis and fibrin deposition. The only comment made about the fetuses was that they were macerated. It is also of note that there 
is an association between SLE and congenital heart block (McCue et al., 1977), although the mechanism by which this develops is unknown. It could be pertinent in some cases of fetal death associated with maternal LA.

It is perhaps paradoxical that the presence of a circulating anticoagulant should be associated with thrombosis, and there is as yet no adequate explanation of this phenomenon (Lubbe et al., 1984), but it does provide an explanation for placental infarction. In this respect placental-bed biopsies from pregnant women with circulating LA would be of particular interest.

Apart from the theoretical and pathophysiological implications of SLE and LA in pregnancy, these data suggest the need to search for LA in patients who suffer repeated second- or third-trimester intrauterine deaths or recurrent firsttrimester abortions, particularly if these are assoicated with placental infarction, since immunosuppression would appear to offer some of these women hope of a successful pregnancy.

These three diseases indicate some of the different ways in which maternal health may affect pregnancy and the differences in the biological processes involved in the pathogenesis of abortion. The reader may find many other diseases discussed in texts on obstetrics and gynecology. In almost all of these examples nothing is known of the nature of the abortus or of the mechanism by which they lead to abortion, although hypotheses abound.

In addition to diseases, dietary factors may be significant. One of the best studied is folic acid (Hibbard and Hibbard, 1971), folic acid supplements being frequently given prophylactically in normal pregnancy. Folic acid antagonists were used for a short period as abortifacient agents (Thiersch, 1952) and in most instances caused fetal death, the fetuses showing depressed hemopoiesis and necrosis of the liver, adrenals, and intestinal epithelium. However, in some instances where fetal death did not occur malformations were produced and this method of termination fell into disrepute.

Martin et al. (1965) described the use of folic acid as a treatment for recurrent abortion. They treated 17 women with folic acid from early pregnancy to term; 15 were delivered of normal term infants and two had satisfactory although undelivered pregnancies. An attempt to use folic acid in the treatment of threatened abortion in seven patients with habitual abortion was entirely unsuccessful. It is possible that the association of intestinal malabsorption with recurrent abortion may be the result of folate deficiency; thus celiac disease has been associated with repeated pregnancy losses (Joske and Martin, 1971).

\subsection{Environmental Factors and Spontaneous Abortion}

It is impossible to cover the subject of environmental agents adequately in a review article, since it would almost certainly require an entire volume. However, 
listing of the entire range of possible agents that might cause abortion would add little to our knowledge, since in the vast majority it would be impossible to confirm, to the satisfaction of most readers, that they caused abortion and it would certainly be impossible to demonstrate the mechanisms by which they acted. Hook and Porter (1980) briefly commented on the relation between environmental hazards, drugs, and embryonic or fetal death and emphasized the problems in proving a cause and effect relation. There is no doubt that environmental factors may have a profound effect on reproduction (Baird, 1980), but the separation of environmental factors from other biological variables presents an almost insurmountable problem except in the experimental animal, where many of the variables may be eliminated. However, there are always doubts about extrapolating animal data to humans. Inevitably there must be some relation between teratogenic agents and abortifacient agents, although the strength of this association is uncertain (Kalter, 1980). Indeed, the teratogenic effects of many environmental hazards are better studied than their effects on pregnancy wastage. Some examples of hazards currently under scrutiny are smoking (Himmelberger et al., 1978; Hemminki et al., 1983a,b), alcohol (Harlap and Shiono, 1980), anesthetic agents (Cohen et al., 1971; Pharoah et al., 1977; Vessey, 1978), radiation (Alberman et al., 1972), pesticides and other agricultural chemicals (Saxena et al., 1980; Townsend et al., 1982; Smith et al., 1982), certain industrial processes (Nordstrom et al., 1974, 1979; Lindbohm et al., 1983), as well as surgical intervention during pregnancy (Saunders and Milton, 1973; Brodsky, 1983). Perhaps of greater concern is the recent demonstration that a drug (diethylstilbestrol) given to the mother of a female infant to prevent abortion may lead to repeated miscarriages and stillbirths in the offspring (Barnes et al., 1980; Schmidt et al., 1980; Veridiano et al., 1981). The reader may draw his or her own conclusions from these data, but all are open to criticism and must be considered with an open mind.

\section{SUMMARY}

It is not yet certain what the true incidence of postfertilization pregnancy wastage is in humans, nor has the overall incidence of chromosomal abnormalities been fully ascertained. In patients presenting with clinically apparent spontaneous abortions less than half the conceptuses have a chromosomal abnormality; however, chromosomal abnormalities remain the most common single finding associated with abortion. They should not be equated with cause, since there is not a clear one-to-one relation between karyotype and abortion. Much research is required if we are to understand the relation between the chromosomal constitution of the conceptus and the eventual outcome of pregnancy, the same being true of anatomical and metabolic abnormalities of the conceptus. The role of chromosomal abnormalities has been overemphasized in the past and to some extent has 
been responsible for supplanting interest in other factors relevant to our understanding of early pregnancy wastage.

Since it is not possible to prevent chromosomal abnormalities arising during gametogenesis, fertilization, and early division of the zygote, it is among the remainder that any salvageable pregnancies are to be found. The many clinical and experimental approaches to abortion require correlation and it should be remembered that they are not mutually exclusive; thus chromosomally abnormal conceptuses may acquire infections or induce an abnormal immune respone in the mother. Infection may be an indication of a breakdown in the normal barriers preventing colonization of the conceptus as may occur in association with cervical incompetence.

Biologically, spontaneous abortion is a physiological process that plays an essential role in human natural selection, and the products of conception are examples of nature's experiments. It is unlikely that any significant reduction in the clinical spontaneous abortion rate will occur until a more scientific analysis of the factors concerned replaces the current somewhat empirical clinical approach. Since few abortions appear to be preventable, it is unlikely that modern antenatal care will be of benefit, but it will be of interest to see if preconception clinics will reduce early pregnancy wastage. For the vast majority of women a spontaneous abortion is an isolated event in their reproductive history, but for a small minority (less than $2 \%$ of women suffering one abortion; D. I. Rushton, unpublished data) it is a recurring problem. These women require special attention not only because of their clinical plight, but also because they may provide new and vital information about the pathophysiology of pregnancy. The odds against a single act of sexual intercourse resulting in a normal full-term live birth are certainly less than even. This is not a chance event, though, and within its complexities there are almost certainly hidden clues to the major problems of later pregnancy: premature labor, preeclamptic toxemia, and intrauterine growth retardation. Unthinking acceptance that we know both the causes and mechanisms of spontaneous abortion is both arrogant and erroneous, since, after death, spontaneous abortion is probably the single most common complication of life even though it appears to involve only half of the human race.

Spontaneous abortions are an extremely heterogeneous population and crude abortion statistics almost certainly conceal important variations within subgroups of this population. These variations are best detected by multidisciplinary studies including morphological examination of both the embryo or fetus and the placenta. Detailed embryological studies do not appear to be warranted, but there is need for understanding of the metabolic processes and their maturation in the embryo or fetus, since such abnormalities may be responsible for intrauterine death in the absence of demonstrable morphological or chromosomal defects.

Further information may be forthcoming from the study of the outcome of pregnancies established in infertile women by ovarian stimulation (Caspi et al., 
1976; Correy et al., 1982) and by embryo transfer (R. G. Edwards and Steptoe, 1983; Kerin et al., 1983). The latter will be of particular immunological interest in that theoretically it will be possible to implant an embryo into a woman who did not contribute to the genetic constitution of that embryo. It is of the utmost importance that all programs in which fertility is treated by hormone therapy, artificial insemination by husband or donor, and by embryo transfer be properly monitored, since where failures occur the abortus may provide essential data that may aid our understanding of pregnancy wastage in women who conceive naturally but abort spontaneously at a later date.

\section{CONCLUSIONS}

1. The majority of spontaneous abortions that are clinically apparent do not have chromosomal anomalies.

2. There is no direct relation between the presence of abnormalities in the embryo or fetus and spontaneous abortion.

3. The vast majority of spontaneous abortions are isolated events in a woman's reproductive life span.

4. The roles of maternal immunological and infective diseases and anatomical abnormalities of the female genital tract in early pregnancy wastage are at best uncertain and at the least controversial.

5. There is a very large void between the epidemiological approach to pregnancy wastage and the biology of spontaneous abortion.

6. Multidisciplinary studies are essential to clarify the interrelation between chromosomal, anatomical, immunological, endocrinological, and biochemical findings in aborted conceptuses.

\section{REFERENCES}

Ahmed, A. G., and Klopper, A. 1984. Detection of subclinical abortion by assay of pregnancy specific $\beta_{1}$ glycoprotein. Br. Med. J. 1:113.

Aladjem, S. 1967. Correlation of pregnancy wastage with hypoplasia of the placental syncytium: Study by phase contrast microscopy. Obstet. Gynecol. 30:408-413.

Aladjem, S. 1975. Examination of fresh villi, in: The Placenta and Its Maternal Supply Line. P. Gruenwald, ed. Medical and Technical Publishing, Lancaster, England, pp. 221-231.

Alberman, E., Polani, P. E., Roberts, J. A. F., Spicer, C. C. Elliott, M., Armstrong, E., and Dhadial, R. K. 1972. Parental X irradiation and chromosome constitution in their spontaneously aborted foetuses. Ann. Hum. Genet. 36:185-194.

Alexander, I., Anthony, F., and Letchworth, A. T. 1982. Placental protein profile and glucose studies in a normal pregnancy with extremely low levels of human placental lactogen: Case report. $\mathrm{Br}$. J. Obstet. Gynaecol. 89:241-243. 
Allen, C. M. 1964, Blood groups and abortions, J. Chron. Dis. 17:619-626.

Anderson, M., Went, L. N., MacIver, J. E., and Dixon, H. G. 1960. Sickle cell disease in pregnancy. Lancet 2:516-521.

Angell, R. R., Sandison, A., and Bain, A. D. 1984. Chromosome variation in perinatal mortality: A survey of 500 cases. J. Med. Genet. 21:39-44.

Anonymous 1980. Outcome of pregnancy after cone biopsy. Br. Med. J. 1:1393-1394.

Anonymous. 1981. Preconception clinics. Br. Med. J. 2:685.

Anonymous. 1982. Vitamins to prevent neural tube defects. Lancet 2:1255-1256.

Anonymous. 1983a. Maternal blocking antibodies, the fetal allograft and recurrent abortion. Lancet 2:1175-1176.

Anonymous. 1983b. Avoiding damage to the cervix. Lancet 2:552-553.

Appelbaum, P. C., Shulman, G., Chambers, N. L., Simon, N. V., Granados, J. L., Fairbrother, P., and Naeye, R. L. 1980. Studies of the growth inhibitory property of amniotic fluids from two United States population groups. Am. J. Obstet. Gynecol. 137:579-582.

Artzt, K. 1983. The $\mathrm{T} / \mathrm{t}$ complex: A family of genes controlling early embryonic surface antigens. Ciba Found. Symp. 96:55-68.

Aspillaga, M. O., Whittaker, P. G., Grey, C. E., and Lind, T. 1983. Endocrinologic events in early pregnancy failure. Am. J. Obstet. Gynecol. 147:903-908.

Awdeh, L., Raum, D., Yunis, E. J., and Alper, C. A. 1983. Extended HLA/complement allelic haplotypes: Evidence for T/t like complex in man. Proc. Natl. Acad. Sci. USA 80:259-263.

Baird, D. 1980. Environment and reproduction. J. Obstet. Gynaecol. 87:1057-1067.

Barnes, A. B., Colton, T., Gunderson, J., Noller, K. L., Tilley, B. C., Strama, T., Townsend, D. E., Hatab, P., and O'Brien, P. C. 1980. Fertility and outcome of pregnancy in women exposed in utero to diethylstilbestrol. New Engl. J. Med. 302:609-613.

Beer, A. E., Quebberman, J. F. Ayers, J. W. T., and Haines, R. F. 1981. Major histocompatability complex antigens, maternal and paternal immune responses and chronic habitual abortions in humans. Am. J. Obstet. Gynecol. 141:987-999.

Bejar, R., Curbello, V., Davis, C., and Gluck, L. 1981. Premature labor. II. Bacterial sources of phospholipase. Obstet. Gynecol. 57:479-482.

Benirschke, K., and Driscoll, S. G. 1967. The Pathology of the Human Placenta. Springer, New York.

Beral, V., Roman, E., and Colwell, L. 1984. Poor reproductive outcome in insulin-dependent diabetic women associated with later development of other endocrine disorders in the mothers. Lancet 1:4-7.

Bissenden, J. G., Ling, N. R., and Machintosh, P. 1980. Suppression of mixed lymphocyte reactions by pregnancy serum. Clin. Exp. Immunol. 39:195-202.

Blanc, W. A. 1981. Pathology of the placenta, membranes and umbilical cord in bacterial, fungal and viral infections in man, in: Perinatal Disease, R. L. Naeye, J. M. Kissane, and N. Kaufman. eds. Williams and Wilkins, Baltimore, pp. 67-132.

Block, S. K. 1978. Occult pregnancy as a factor in unexplained infertility. J. Reprod. Med. 21:251253.

Bobbitt, J. R., and Ledger, W. J. 1976. Obstetric observations in eleven cases of neonatal sepsis due to group B $\beta$-hemolytic streptococcus Obstet. Gynecol. 47:439-442.

Brodsky, J. B. 1983. Anaesthesia and surgery during early pregnancy and fetal outcome. Clin. Obstet. Gynecol. 26:449-457.

Burdi, A. R., Barr, M., Work, B. A., and Bloom, A. D. 1974. Monitoring the human abortus for developmental defects. Cleft Palate J. 11:105-110.

Burns, J., and Gibbons, D. 1978. May spina bifida result from an X-linked defect in a selective abortion mechanism? Heredity 41:424.

Carr, D. H. 1963. Chromosome studies in abortuses and stillborn infants. Lancet 2:603-606. 
Carr, D. H., Bateman, A. J., and Murray, A. B. 1966. Analysis of data from abortuses which failed to grow in culture. Obstet. Gynecol. 28:611-614.

Carreras, L. O., Vormylen, J., Spitz, B., and Assche, A. V. 1981. Lupus anticoagulant and inhibition of prostacyclin formation in patients with repeated abortion, intrauterine growth retardation and intrauterine death. Br. J. Obstet. Gynaecol. 88:890-894.

Caspi, E., Ronen, J., Schreyer, P., and Goldberg, M. D. 1976. The outcome of pregnancy after gonadotrophin therapy. Br. J. Obstet. Gynaecol. 83:967-973.

Chard, T., and Klopper, A. 1982. Placental Function Tests. Springer, Berlin.

Chartier, M., Roger, M., Barrat, J., and Michelon, B. 1979. Measurement of plasma HCG and $\beta$ HCG activities in the late luteal phase: Evidence of the occurrence of spontaneous menstrual abortions in fertile women. Fertil. Steril. 31:134-137.

Cohen, B. H., and Sayre, J. E. 1968. Further observations on the relationship of maternal ABO and Rh types to fetal death. Am. J. Hum. Genet 20:310-360.

Cohen, E. N., Bellville, J. W., and Brown, B. W. 1971. Anesthesia, pregnancy, and miscarriage: A study of operating room nurses and anesthetists. Anesthesiology 35:343-347.

Colvin, E. D., Bartholomew, R. A., Grimes, W. H., and Fish, J. S. 1950. Salvage possibilities in threatened abortion. Am. J. Obstet. Gynecol. 59:1208-1222.

Correy, J. F., Marsden, D. E., and Schokman, F. C. 1982. The outcome of pregnancy resulting from clomiphene induced ovulation. Aust. N. Z. J. Obstet. Gynaecol. 22:18-21.

Cousins, L. 1980. Cervical incompetence 1980: A time for reappraisal. Clin. Obstet. Gynecol. 23:467-479.

Crane, J. P., and Wahl, N. 1981. The role of maternal diabetes in repetetive spontaneous abortion. Fertil. Steril. 36:477-479.

Creasy, M. R., and Alberman, E. D. 1976. Congenital malformations of the central nervous system in spontaneous abortions. J. Med. Genet. 13:9-16.

Daker, M. 1983. Chorionic tissue biopsy in the first trimester of pregnancy. Br. J. Obstet. Gynaecol. 90:193-195.

Daria-Haust, M. 1981. Maternal diabetes mellitus-effects on the fetus and placenta, in: Perinatal Diseases, R. L. Naeye, J. M. Kissane, and N. Kaufman, eds. Williams and Wilkins, Baltimore, pp. 201-285.

Day, R. E., and Insley, J. 1976. Maternal diabetes mellitus and congenital malformation: Survey of 205 cases. Arch. Dis. Child. 51:935-938.

Dehner, L. P., and Askin, F. B. 1975. Cytomegalovirus endometritis: Report of a case associated with spontaneous abortion. Obstet. Gynecol. 45:211-214.

Desa, D. J., and Trevenen, C. L. 1984. Intrauterine infections with group B $\beta$-haemolytic streptococci. Br. J. Obstet. Gynaecol. 91:237-239.

Diczfalusy, E. 1974. Steps in the human reproductive process susceptible to immunological interference, in: Karolinska Symposia on Research Methods in Reproductive Endocrinology, E. Diczfalusy, ed. Karolinska Institutet, Stockholm, pp. 13-37.

Duff, G. B., Evans, J. J., and Legge, M. 1980. A study of investigations used to predict the outcome of pregnancy after threatened abortion. Br. J. Obstet. Gynaecol. 87:194-198.

Eckman, T. R., and Carron, L. J. 1962. Placental lesions in spontaneous abortions. Am. J. Obstet. Gynecol. 84:222-228.

Edlow, J. B., Huddleston, J. F., Lee, G., Peterson, W. F., and Robinson, J. C. 1971. Multiple enzyme deficiencies in placental tissue from two blighted ovum abortions. Am. J. Obstet. Gynecol. 111:365-368.

Edwards, J. H., Yuncken, C., Rushton, D. I., Richards, S., and Mittwoch U. 1967. Three cases of triploidy in man. Cytogenetics 6:81-104.

Edwards, R. G., and Steptoe, P. C. 1983. Current status of in-vitro fertilisation and implantation of human embryos. Lancet 2:1265-1269. 
Edwards, R. G., Howe, C. W. S., and Johnson, M. H., eds. 1975. Immunobiology of Trophoblast. Cambridge University, London.

Eisinger, S. H. 1976. Second trimester spontaneous abortion, IUD and infection. Am. J. Obstet. Gynecol. 124:393-397.

Elias, S., and Simpson, J. L., 1980. Evaluation and management of patients at apparent increased risk of spontaneous abortion, in: Human Embryonic and Fetal Death, I. H. Porter and E. B. Hook, eds. Academic, New York, pp. 331-353.

Evaldson, G. R., Malmborg, A. S., and Nord, C. E. 1982. Premature ruputre of the membranes and ascending infection. Br. J. Obstet. Gynaecol. 89:793-801.

Fantel, A. G., Shepard, T. H., Vadheim Roth, C., Stephens, T. D., and Coleman, C. 1980. Embryonic and fetal phenotypes: Prevalence and other factors in a large study of spontaneous abortion, in: Human Embryonic and Fetal Death, I. H. Porter and E. B. Hook, eds. Academic, New York, pp. 71-87.

Feeney, J. G., and Scott, J. S. 1980. Pre-eclampsia and changed paternity. Eur. J. Obstet. Gynaecol. Reprod. Biol. 11:35-38.

Finberg, H. J., and Birnholz, M. D. 1979. Ultrasound observations in multiple gestation with first trimester bleeding: The blighted twin. Radiology 132:137-142.

Gans, B., Eckerling, B., and Goldman, J. A. 1966. Abortion due to incompetence of internal os of the cervix. Obstet. Gynecol. 27:875-879.

Geisler, M., and Kleinebrecht, J. 1978. Cytogenetic and histologic analyses of spontaneous abortions. Hum. Genet. 45:239-251.

Gelabert, A., Balasch, J., Ercilla, G., Vanrell, J. A., Vives, J., Gonzalez-Merlo, J., and Icios, de H. 1981. Abortion may sensitize the mother to HLA antigens. Tiss. Antigens 17:353-356.

Gerencer, M., Kastelan, A., Drazancic, A., Kerhin-Brkljacicic, V., and Madjaric, M. 1978. The HLA antigens in women with recurrent abnormal pregnancies of unknown etiology. Tiss. Antigens 12:223-227.

Glass, R. H., and Golbus, M. S. 1978. Habitual abortion. Fertil Steril. 29:257-265.

Goldman, J. A., and Resnik, R. 1974. Carbohydrate metabolism in previable fetal death. Am. J. Obstet. Gynecol. 119:1083-1090.

Goldzieher, J. W. 1964. Double blind trial of a progestin in habitual abortion. J. Am. Med. Ass. 188:651-654.

Goldzieher, J. W., and Benigno, B. B. 1958. The treatment of threatened and recurrent abortion: A critical review. Am. J. Obstet. Gynecol. 75:1202-1214.

Greiss, F. C., and Mauzy, C. H. 1961. Genital anomalies in women: An evaluation of diagnosis, incidence and obstetric performance. Am. J. Obstet. Gynecol. 82:330-339.

Griffin, J. F. T., and Beck, I. 1983. A longitudinal study of leucocyte numbers and mitogenesis during the last ten weeks of human pregnancy. J. Reprod. Immunol. 5:239-247.

Griffiths, P. D., and Baboonian, C. 1984. A prospective study of primary cytomegalovirus infection during pregnancy: Final report. Br. J. Obstet. Gynaecol. 91:307-315.

Grogan, T. M., Broughton, D. D., and Doyle, W. F. 1975. Graft-versus-host reaction (GVHR): A case report suggesting GVHR occurred as a result of maternofetal cell transfer. Arch. Pathol. 99:330-334.

Gronroos, M., Honkonen, E. Terho, P., and Punnonen, R. 1983. Cervical and serum $\mathrm{I}_{\mathrm{g}} \mathrm{A}$ and serum $\mathrm{I}_{\mathrm{g}} \mathrm{G}$ antibodies to Chlamydia trachomatis and herpes simplex virus in threatened abortion: $\mathrm{A}$ prospective study. Br. J. Obstet. Gynaecol. 90:167-170.

Hafez, E. S. E. 1967. Reproductive failure in domestic animals, in: Comparative Aspects of Reproductive Failure, K. Benirschke, ed. Springer, New York, pp. 42-95.

Hall, F. B., and Meyer, A. W. 1921. Studies on abortuses: Survey of pathological ova in Carnegie embryological collections. Contrib. Embryol. 12:1-364. 
Hancock, J. L., McGovern, P. T., and Stamp, J. T. 1968. Failure of gestation of goat $\times$ sheep hybrids in goats and sheep. J. Reprod Fertil Suppl. 3:92-96.

Harkness, R. A., Taylor, N. F., Crawford, M. A., and Rose, F. A. 1983. Recognising placental steroid sulphatase deficiency. Br. Med. J. 2:2-3.

Harlap, S., and Shiono, P. H. 1980. Alcohol, smoking and incidence of spontaneous abortions in the first and second trimester. Lancet 2:173-176.

Harlap, S., Shiono, P. H., and Ramcharan, S. 1980. Spontaneous fetal losses in women using different contraceptives around the time of conception. Int. J. Epidemiol. 9:49-56.

Hartikainen-Sorri, A. L., and Kaila, J. 1980. Systemic lupus erythematosus and habitual abortion. Br. J. Obstet. Gynaecol. 87:729-731.

Hassan, S. 1965. A vaginal smear study in cases of threatened abortion. J. Obstet. Gynaecol. Br. Comm. 72:416-421.

Hassold, T. J., Matsuyama, A., Newlands, I. M., Matsuvra, J. S., Jacobs, P. A., Manuel, B., and Tsuei, J. 1978. A cytogenetic study of spontaneous abortions in Hawaii. Ann. Hum. Genet. 41:443-454.

Haxton, M. J., and Bell, J. 1983. Fetal anatomical abnormalities and other associated factors in middle trimester abortions and their relevance to patient counselling. Br. J. Obstet. Gynaecol. 90:501-506.

Hay, D. 1958. The diagnosis and significance of minor degrees of uterine abnormality in relation to pregnancy. J. Obstet. Gynaecol. Br. Emp. 65:557-582.

Hellman, K. 1966. Immunosuppression by thalidomide: Implications for teratology. Lancet 1:11361137.

Hemminki, K., Mutanen, P., Saloniemi, I., Niemi, M. L., and Vaino, H. 1982. Spontaneous abortions in hospital staff engaged in sterilising instruments with chemical agents. Br. Med. J. 2:1461-1463.

Hemminki, K., Axelson, O., Niemi, M. H., and Ahlborg, G. 1983a. Assessment of methods and results of reproductive occuptaional epidemiology: Spontaneous abortions and malformations in the offspring of working women. Prog. Clin. Biol. Res. 117:293-307.

Hemminki, K., Mutanen, P., and Saloniemi, I. 1983b. Smoking and occurrence of congenital malformations and spontaneous abortions: Multivariate analysis. Am. J. Obstet. Gynecol. 145:6166.

Hensleigh, P. A., and Fainstat, T. 1979. Corpus luteum dysfunction: Serum progesterone levels and assessment of therapy for recurrent and threatened abortion. Fertil. Steril. 32:396-400.

Hertig, A. T., and Sheldon, W. H. 1943. Minimal criteria required to prove prima facie case of traumatic abortion or miscarriage; An analysis of 1000 spontaneous abortions. Ann. Surg. 117:596-606.

Hibbard, B. M., and Hibbard, E. D. 1971. Folate metabolism and reproduction. J. Physiol. 219:16P.

Himmelberger, D. U., Brown, B. W., and Cohen, E. N. 1978. Cigarette smoking during pregnancy and the occurrence of spontaneous abortion and congenital abnormality. Am. J. Epidemiol. 108:470-479.

Hogarth, P. J., 1982. Immunological Aspects of Mammalian Reproduction. Praeger, New York.

Honoré, L. H., Dill, F. J., and Poland, B. J. 1976. Placental morphology in spontaneous human abortuses with normal and abnormal karyotypes. Teratology 14:151-166.

Hook, E. B., 1981. Prevalence of chromosome abnormalities during human gestation and implications for study of environmental mutagens. Lancet 2:169-172.

Hook, E. G., and Porter, I. H. 1980. Terminological conventions, methological considerations, temporal trends, specific genes, environmental hazards and some other factors pertaining to embryonic and fetal death, in: Human Embryonic and Fetal Death, I. H. Porter and E. B. Hook, eds. Academic, New York, pp. 1-17. 
Huber, C. P., Melin, J. R., and Vellios, F. 1975. Changes in the chorionic tissue of aborted pregnancy. Am. J. Obstet. Gynecol. 73:569-578.

Hughes, G. R. V. 1983. Thrombosis, abortion, cerebral disease and lupus anticoagulant. Br. Med. J. 2:1088-1089.

Jackson, G., Pendleton, H. J., Nichol, B., and Wittmann, B. K. 1984. Diagnostic ultrasound in the assessment of patients with incompetent cervix. Br. J. Obstet. Gynaecol. 91:232-236.

Jaschevatzky, O. E., Shalit, A., Grunstein, S., Kaplanski, J., and Danon, A. 1983. Increased decidual prostaglandin E concentration in human abortion. Br. J. Obstet. Gynaecol. 90:958-960.

Javert, C. T. 1962. Further follow up on habitual abortion patients. Am. J. Obstet. Gynecol. 84:1149-1156.

Jeffcoate, T. N. A., and Wilson, J. K. 1956. Uterine causes of abortion and premature labour. $N$. Y. State J. Med. 56:680-690.

Jenkins, D. M. 1976. Pre-eclampsia/eclampsia (gestosis) and other pregnancy complications with a possible immunologic basis, in: Immunology of Human Reproduction, J. S. Scott and W. R. Jones, eds. Academic, London, pp. 297-327.

Jennings, C. L. 1972. Temporary submucosal cerclage for cervical incompetence: Report of forty eight cases. Am. J. Obstet. Gynecol. 113:1097-1102.

Johansen, K., and Festenstein, H. 1974. Possible relationships between maternal HL-A antibody formation and fetal sex: Evidence for a sex linked histocompatability system in man. J. Obstet. Gynaec. Br. Comm. 81:781-785.

Jones, G. S. 1975. Luteal phase defects, in: Progress in Infertility, S. J. Behrman and R. W. Kistner, eds. Little, Brown, Boston, p. 299.

Jones, G. S. 1976. The luteal phase defect. Fertil. Steril. 27:351-356.

Jones, G. S., and Pourmand, K. 1962. An evaluation of etiologic factors and therapy in 555 private patients with primary infertility. Fertil. Steril. 13:398-410.

Jones, H. W., and Jones, G. E. S. 1953. Double uterus as an etiological factor in repeated abortion: Indications for surgical repair. Am. J. Obstet. Gynecol. 65:325-339.

Joske, R. A., and Martin, J. D. 1971. Coeliac disease presenting as recurrent abortion. J. Obstet. Gynaecol. Br. Comm. 78:754-758.

Kadowaki, J., Thomspon, R. I., Zuelzer, W. W., Woolley, P. V., Brough, A. J., and Gruber, D. 1965. XX/XY lymphoid chimaerism in congenital immunological deficiency syndrome with thymic alymphoplasia. Lancet 2:1152-1156.

Kalter, H. 1980 The relation between congenital malformations and prenatal mortality in experimental animals, in: Human Embryonic and Fetal Death, I. H. Porter and E. B. Hook, eds. Academic, New York, pp. 29-44.

Kajii, T., Ferrier, A., Niikawa, N., Takahara, H., Ohama, K., and Avirachan, S. 1980. Anatomic and chromosomal anomalies in 639 spontaneous abortuses. Hum. Genet. 55:87-98.

Kajii, T., and Ohama, K. 1977. Androgenetic origin of hydatidiform mole. Nature 268:633-634.

Karim, S. M. M., and Devlin, J. 1967. Prostaglandin content of amniotic fluid during pregnancy and labour. Br. J. Obstet. Gynaecol. 74:230-234.

Karim, S. M. M., and Hillier, K. 1970. Prostaglandins and spontaneous abortion. Br. J. Obstet. Gynaecol. 77:837-839.

Kerin, J. F., Warnes, G. H., Quinn, P. J., Jeffrey, R., Kirby, C., Matthews, C. D., Seamark, R. F., and Cox, L. W. 1983. Incidence of multiple pregnancy after in-vitro fertilisation and embryo transfer. Lancet 2:537-540.

Khakpour, M., Saidi, A., and Naficy, K. 1969. Proved viraemia in Asian influenze (Hong Kong variant) during incubation perod. Br. Med. J. 4:208-209.

Kim-Farley, R. J., Cates, W., Ory, H. W., and Hatcher, R. A. 1978. Febrile spontaneous abortion and the IUD. Contraception 18:561-570. 
Kissane, J. M. 1981. Reproductive failure: A survey of pathogenic mechanisms with emphasis on mechanisms for repeated failures, in: Perinatal Diseases, R. L. Naeye, J. M. Kissane, and N. Kaufman, eds. Williams and Wilkins, Baltimore, pp. 369-381.

Kline, J., Stein, Z., Strobino, B., Susser, M., and Warburton, D. 1977. Surveillance of spontaneous abortions: Power in environmental monitoring. Am. J. Epidemiol. 106:345-350.

Kline, J., Shrout, P., Stein, Z., Susser, M., and Warburton, D. 1980. Drinking during pregnancy and spontaneous abortion. Lancet 2:176-180.

Knill-Jones, R. P., Newman, B., and Spence, A. A. 1975. Anaesthetic practice and pregnancy. Lancet 2:807-809.

Kurjak, A., and Kirkinen, P. 1982. Ultrasonic growth pattern of fetuses with chromosomal aberrations. Acta Obstet. Gynecol. Scand. 61:223-225.

Lash, A. F., and Lash, S. R. 1950. Habitual abortion: The incompetent internal os of the cervix. Am. J. Obstet. Gynecol. 59:68-76.

Lauritsen, J. G., Grunnet, N., and Jonson, O. M. 1975. Maternal-fetal ABO incompatability as a cause of spontaneous abortion. Clin. Genet. 7:308-316.

Lauritsen, J. G., Kistensen, T., and Grarnet, N. 1976. Depressed mixed lymphocyte culture reactivity in mothers with recurrent spontaneous abortion. Am. J. Obstet. Gynecol. 125:35-39.

Lenz, W., and Knapp, K. 1962. Foetal malformations due to thalidomide. Germ. Med. Mon. 7:253258.

Liggins, G. C., Forster, C. S., Grieves, S. A., and Schwartz, A. L. 1977. Control of parturition in man. Biol. Reprod. 16:39-56.

Lilienfeld, A. M., and Pasamanick, B. 1955. The association of maternal and fetal factors with the development of cerebral palsy and epilepsy. Am. J. Obstet. Gynecol. 70:93-101.

Lindbohm, M. I., Hemminki, K., Kyyr-onen, P., Kilpikari, I., and Vainio. H. 1983. Spontaneous abortions among rubber workers and congenital malformations in their offspring. Scand. $J$. Work Environ. Health (Suppl.) 9:285-290.

Lubbe, W. F., Butler, W. S., Palmer, S. J., and Liggins, G. C. 1983. Fetal survival after prednisone suppression of maternal lupus anticoagulant. Lancet 1:1361-1363.

Lubbe, W. F., Butler, W. S., Palmer, S. J., and Liggins, G. C. 1984. Lupus anticoagulant in pregnancy. Br. J. Obstet. Gynaecol. 91:357-363.

MacNaughton, M. C. 1976. Hormone assays in early pregnancy, in: Plasma Hormone Assays in Evaluation of Fetal Wellbeing, A. Klopper, ed. Churchill-Livingstone, London, pp. 36-47.

Mantoni, M., and Pedersen, J. F. 1982. Fetal growth delay in threatened abortion: An ultrasound study. Br. J. Obstet. Gynaecol. 89:525-527.

Martin, R. H., Harper, T. A., and Kelso, W. 1965. Serum folic acid in recurrent abortions. Lancet 1:670-672.

Matsunaga, E., and Shiota, K. 1979. Threatened abortion, hormone therapy and malformed embryos. Teratology 20:469-479.

Matsunaga, E., and Shiota, A. 1980. Ectopic pregnancy and myoma uteri: Teratogenic effects and maternal characteristics. Teratology 21:61-69.

McCue, C. M., Mantakas, M. E., Tingelstad, J. B., and Ruddy, S. 1977. Congenital heart block in newborns of mothers with connective tissue disease. Circulation 56:82-90.

McIntyre, J. A., and Faulk, W. P. 1982. Allotypic trophoblast-lymphocyte cross reactive (TLX) cell surface antigens. Hum. Immunol. 4:27-35.

Mikamo, K. 1970. Anatomic and chromosomal anomalies in spontaneous abortions. Am. J. Obstet. Gynecol. 106:243-254.

Miller, J. F., Williamson, E., Glue, J., Gordon, Y. B., Grudzinkas, J. D., and Sykes, A. 1980. Fetal loss after implanation. Lancet 2:554-556.

Miller, J. M., Pupkin, M. J., and Hill, G. B. 1980. Bacterial colonization of amniotic fluid from intact fetal membranes. Am. J. Obstet. Gynecol. 136:796-804. 
Miller, J. R., and Poland, B. J. 1970. The value of human abortuses in the surveillance of developmental anomalies. I. General overview. Can. Med. Ass. J. 103:501-502.

Naeye, R. L. 1980. Coitus and associated amniotic fluid infections. New Engl. J. Med. 301:11981200.

Naeye, R. L., and Blanc, W. A. 1970. Relation of poverty and race to antenatal infection. N. Engl. J. Med. 283:555-560.

Naeye, R. L., and Peters, E. C. 1978. Amniotic fluid infections with intact membranes leading to perinatal death: A prospective study. Pediatrics 61:171-177.

Naeye, R. L., Blanc, W. A., and Paul, C. 1973. Effects of maternal nutrition of the human fetus. Pediatrics 52:494-503.

Need, J. A. 1975. Pre-eclampsia in pregnancies by different fathers: Immunological studies. $\mathbf{B r}$. Med. J. 1:548-549.

Nielsen, P. V., Pedersen, H., and Kampmann, E. M. 1979. Absence of human placental lactogen in an otherwise uneventful pregnancy. Am. J. Obstet. Gynaecol. 135:322-326.

Nilsson, I. M., Astedt, B., Hedner, U., and Berezin, D. 1975. Intrauterine death and circulating anticoagulant (antithromboplastin). Acta Med. Scand. 197:153-159.

Nishimura, H., Takano, K., Tanimura, T., Yasuda, M., and Uchida, T. 1966. High incidence of several malformations in early embryos as compared with infants. Biol. Neonat. 10:93-107.

Nishimura, H., Takano, K., Tanimura, T., and Yasuda, M. 1968. Normal and abnormal development of human embryos: First report on the analysis of 1213 embryos. Teratology 1:281290.

Nixon, G. S., Helsby, C. A., Gordon, H., Hytten, F. E., and Renson, C. E. 1979. Pregnancy outcome in female dentists. Br. Dent. J. 146:39-42.

Nordstrom, S., Beckman, L., and Nordensen, I. 1974. Occupational and environmental risks in and around a smelter in northern Sweden. III. Frequencies of spontaneous abortion. Hereditas 88:51-54.

Nordstrom, S., Beckman, L., and Nordensen, I. 1979. Occupational and environmental risks in and around a smelter in northern Sweden. V. Spontaneous abortion among female employees and decreased birthweight of their offspring. Hereditas 90:291-296.

Oakley, G. P. 1975. The use of human abortuses in the search for teratogens, in: Methods for Detection of Environmental Agents That Produce Congenital Defects, T. H. Shepard, ed. NorthHolland, Amsterdam, pp. 189-196.

Ornoy, A., Salamon-Arnon, J., Benzur, Z., and Kohn, G. 1981. Placental findings in spontaneous abortions and stillbirths. Teratology 24:243-252.

Parmiani, G., and Della Porta, G. 1973. Effects of antitumour immunity on pregnancy in the mouse. Nature 241:26-28.

Pearse, W., and Lau, G. F. 1963. ABO incompatible pregnancies and reproductive performance. Int. J. Fertil. 8:495-502.

Pedersen, J. F. 1983. Fetal size in early pregnancy and congenital malformation. Am. J. Obstet. Gynecol. 145:641-642.

Perlman, M., Williams, J., and Hirsch, H. 1976. Neonatal pulmonary hypoplasia after prolonged leakage of amniotic fluid. Arch. Dis. Child. 51:349-353.

Perlmutter, J. F. 1978. Pregnancy and the IUD. J. Reprod. Med. 20:133-138.

Pettersson, F. 1968. Epidemiology of Early Pregnancy Wastage. Svenska Bokforlaget, NorstedtsBonniers, Stockholm, p. 25.

Pharoah, P. O., Alberman, E., Dolye, P., and Chamberlain, G. 1977. Outcome of pregnancy among women in anaesthetic practice. Lancet 1:34-36.

Piver, M. S., Bolognese, R. J., and Feldman, J. D. 1967. Long acting progesterone as a cause of missed abortion. Am. J. Obstet. Gynecol. 97:579-581. 
Poland, B. J. 1968. Study of developmental anomalies in the spontaneously aborted fetus. Am. J. Obstet. Gynecol. 100:501-505.

Poland, B. J., and Lowry, R. B. 1974. The use of spontaneous abortuses and stillbirths in genetic counseling. Am. J. Obstet. Gynecol. 118:322-326.

Poland, B. J., and Yuen, B. H. 1978. Embryonic development in consecutive specimens from recurrent spontaneous abortions. Am. J. Obstet. Gynecol. 130:512-515.

Poland, B. J., Dill, F. J., and Styblo, C. 1976. Embryonic development in ectopic human pregnancy. Teratology 14:315-321.

Poland, B. J., Miller, J. R., Harris, M., and Livingston, J. 1981. Spontaneous abortion: A study of 1961 women and their conceptuses. Acta Obstet. Gynecol. Scand. (Suppl.) 102:5-32.

Power, D. A., Catto, G. R. D., Mason, R. J., MacLoed, A. M., Stewart, G. M., Stewart, K. N., and Shewan, W. G., 1983. The fetus as an allograft: Evidence for protective antibodies to HLAlinked paternal antigens. Lancet 2:701-704.

Quagliarello, J. Szlachter, N., Nisselbaum, J. S., Schwartz, M. K., Steinetz, B., and Weiss, G. 1981. Serum relaxin and HCG concentrations in spontaneous abortions. Fertil. Steril. 36:399-401.

Redman, C. W. G., Bodmer, W. R., Bodmer, J. G., Beilin, L. J., and Bonnar, L. 1978. HLA antigens in severe pre-eclampsia. Lancet 2:397-399.

Robertson, W. B. 1976. Uteroplacental vasculature. J. Clin. Pathol. 29 (Suppl. 10):9-17.

Robertson, W. B., Brosens, I., and Dixon, H. G. 1967. The pathological response of the vessels of the placental bed to hypertensive pregnancy. J. Pathol. Bacteriol. 93:581-592.

Robinson, H. P. 1975. Diagnosis of early pregnancy failure by sonar. Br. J. Obstet. Gynaecol. 82:849-857.

Rosenberg, H. S., Kohl, S., and Vogler, C. 1981. Viral infections of the fetus and neonate, in: Perinatal Diseases, R. L. Naeye, J. H. Kissane, and N. Kaufman, eds. Williams and Watkins, Baltimore, pp. 133-200.

Ross, G. T. 1979. Human chorionic gonadotrophin and maternal recognition of pregnancy. Ciba Found. Symp. 64:191-201.

Rosztocy, I., Sweet, C., Toms, G. L., and Smith, H. 1975. Replication of influenza virus in organ cultures of human and simian urogenital tissues and human foetal tissues. Br. J. Exp. Pathol. 56:322-328.

Rushton, D. I. 1978. Simplified classification of spontaneous abortions. J. Med. Genet. 15:1-9.

Rushton, D. I., 1981. Examination of products of conception from pre-viable human pregnancies. J. Clin. Pathol. 34:819-835.

Rushton, D. I. 1982. Examination of abortions, in: Fetal and Neonatal Pathology, A. J. Barson, ed. Praeger, Eastbourne, pp. 27-64.

Rushton, D. I. 1984. The classification and mechanisms of spontaneous abortions. in: Perspectives in Pediatric Pathology, H. S. Rosenberg and R. P. Bolande, eds. Masson, New York, Vol. 8 pp. 269-287.

Rushton, D. I., Collie, M. H., Sweet, C., Husseini, R. H., and Smith, H. 1983. The effects of maternal influenzal viraemia in late gestation on the conceptus of the pregnant ferret. J. Pathol. 140:181-191.

Russel, P. 1979. Inflammatory lesions of the human placenta. 1. Clinical significance of acute chorioamnionitis. Am. J. Diag. Gynecol. Obstet. 1:127-137.

Russell, P., Atkinson, K., and Krishnan, L. 1980. Recurrent reproductive failure due to severe placental villitis of unknown etiology. J. Reprod. Med. 24:93-98.

Ryan, K. J. 1980. Placental synthesis of steriod hormones, in: Maternal-Fetal Endocrinology, D. Tulchinsky and K. J. Ryan, eds. Saunders, Philadelphia, pp. 3-16.

Sadovsky, A., and Laufer, A. 1961. Placental changes in early spontaneous abortion. Obstet. Gynecol. 17:678-683. 
Salhan, S. A., Mehrotra, M. L., and Dube, S. 1979. Histopathological study of placenta and decidua in midtrimester abortions. J. Obstet. Gynecol. India 29:811-814.

Saunders, P., and Milton, P. J. D. 1973. Laparotomy during pregnancy: An assessment of diagnostic accuracy and fetal wastage. Br. Med. J. 3:165-167.

Saxena, M. C., Siddiqui, M. K. J., Bhargana, A. K., Seth, T. D., Krishnamurti, C. R., and Kutty, D. 1980. Role of chlorinated hydrocarbon pesticides in abortions and premature labour. Toxicology 17:323-332.

Schacter, B., Muir, A., Gyves, A., and Tasin, M. 1979. HLA-A,B compatability in parents of offspring with neural tube defects or couples experiencing involuntary fetal wastage. Lancet 1:796-799.

Schardein, J. L. 1980. Congenital abnormalities and hormones during pregnancy: A clinical review. Teratology 22:251-270.

Schmidt, G., Fowler, W. G., Talbert, L. M., and Edelman, D. A. 1980. Reproductive history of women exposed to diethylstilboestrol in utero. Fertil. Steril. 33:21-24.

Schweditsch, M. O., Dubin, N. H., Jones, G. S., and Wentz, A. C. 1979. Hormonal considerations in early normal pregnancy and blighted ovum syndrome. Fertil. Steril. 31:252-257.

Scott, J. S., and Jones, W. R., eds. 1976. Immunology of Human Reproduction. Academic, London.

Shearman, R. P., and Garrett, W. J. 1963. Double blind study of the effect of 17-hydroxyprogesterone caproate on abortion rate. Br. Med. J. 1:292-295.

Sheppard, B. L., and Bonnar, J. 1976. The ultrastructure of the arterial supply of the human placenta in pregnancy complicated by fetal growth retardation. Br. J. Obstet. Gynaecol. 83:948959.

Shiota, K., Chous, M. J., Fukushima, H., and Tanimura, T. 1975. Malformations found in early human fetuses. Teratology 12:21-26.

Sideri, M., de Virgiliis, G., Guidobono, F., Bergese, N., Sereni, L., Nicolini, U., and Remotti, G. 1983. Immunologically undetectable human placental lactogen in a normal pregnancy: Case report. Br. J. Obstet. Gynaecol. 90:771-773.

Singh, R. P., and Carr, D. H. 1967. Anatomic findings in human abortions of known chromosomal constitution. Obstet. Gynecol. 29:806-818.

Singh, R. P., and Carr, D. H. 1968. Congenital anomalies in embryos with normal chromosomes. Biol. Neonat. 13:121-128.

Slade, B. 1973. Antibodies to alpha-fetoprotein cause fetal mortality in rabbits. Nature 246:493.

Smith, A. H., Fisher, D. O., Pearce, N., and Chapman, C. J. 1982. Congenital defects and miscarriages among New Zealand 2,4,5-T sprayers. Arch. Environ. Health 37:197-200.

South, J. 1972. Maternal influenza and perinatal mortality. Br. Med. J. 2:464-465.

Stein, Z., Susser, M., Warburton, D., Wittes, J., and Kline, J. 1975. Spontaneous abortion as a screening device: The effect of fetal survival on the incidence of birth defects. Am. J. Epidemiol. 102:275-290.

Stirrat, G. M. 1980. The immunological system, in: Clinical Physiology in Obstetrics, F. Hytten and G. Chamberlain, eds. Blackwell, Oxford, pp. 101-144.

Stirrat, G. M. 1983. Recurrent abortion-a review. Br. J. Obstet. Gynaecol. 90:881-883.

Suciu-Foca, N., Reed, E., Rohowsky, C., Kung, P. and King, D. W. 1983. Anti-idiotypic antibodies to anti-HLA receptors induced by pregnancy. Proc. Natl. Acad. Sci. USA 80:830-834.

Sunderland, C. A., Naiem, M., Mason, D. Y., Redman, G. W. G., and Stirrat, G. M. 1981a. The expression of major histocompatability antigens by human trophoblast. J. Reprod. Immunol. 3:323-331.

Sunderland, C. A., Redman, C. W. G., and Stirrat, G. M. 1981b. HLA-A.B.C. are expressed on nonvillous trophoblast of the early human placenta. J. Immunol. 127:2614-2615.

Takahara, H. Ohama, K., and Fujiwara, A., 1977. A cytogenetic study in early spontaneous abortion. Hiroshima J. Med. Sci. 26:291-296. 
Takano, K., and Miller, J. R. 1972. ABO incompatability as a cause of spontaneous abortion: Evidence from abortuses. J. Med. Genet. 9:144-150.

Takeuchi, S. 1980. Immunology of spontaneous abortion and hydatidiform mole. Am. J. Reprod. Immunol. 1:23-28.

Takeuchi, S. 1983. Immunology of growth and demise of embryo-trophoblast unit indicated by comparative study between abortion and hydatidiform mole, in: Immunobiology of Transplantation, Cancer and Pregnancy, P. K. Ray, ed. Pergamon, New York, pp. 305-331.

Tanimura, T. 1972. Internal anomalies combined with external malformations in human embryos. Teratology 6:121-122.

Taylor, C., and Faulk, W. P. 1981. Prevention of recurrent abortion with leucocyte transfusions. Lancet 1:68-70.

Thiersch, J. B. 1952. Therapeutic abortions with a folic acid antagonist 4-aminopteroylglutamic acid (4-amino P.G.A), administered by the oral route, Am. J. Obstet. Gynecol. 63:1298-1304.

Tho, P. T., Byrd, J. R., and McDonough, P. G. 1979. Etiologies and subsequent reproductive performance of 100 couples with recurrent abortion. Fertil. Steril. 32:389-395.

Thomas, A. K. 1975. Septic abortion associated with a Lippes loop. Br. Med. J. 3:747-748.

Townsend, J. C., Bodner, K. M., Van Peensen, P. F. D., Olson, R. D., and Cook, R. R. 1982. Survey of reproductive events of wives of employees exposed to chlorinated dioxins. Am. J. Epidemiol. 115:695-713.

Tuck, S. M., Studd, J. W. W., and White, J. M. 1983. Pregnancy in sickle cell disease in the U.K. Br. J. Obstet. Gynaecol. 90:112-117.

Uchida, I. A., Freeman, V. C. P., Gedeon, M., and Goldmaker, J. 1983. Twinning rate and spontaneous abortions. Am. J. Hum. Genet. 35:987-993.

Varma, T. 1979. Ultrasound evidence of early pregnancy failure in patients with multiple conceptions. Br. J. Obstet. Gynaecol. 86:290-292.

Veridiano, N P., Delke, I., Rogers, J., and Tancer, M. I. 1981. Reproductive performance of DES exposed female progeny. Obstet. Gynecol. 58:58-61.

Vessey, M P. 1978. Epidemiological studies of the occupational hazards of anaesthesia-a review. Anaesthesia 33:430-438.

Warburton, D., Stein, Z., Kline, J., and Susser, M. 1980. Chromosome abnormalities in spontaneous abortions: Data from the New York Study, in: Human Embryonic and Fetal Death, I. H. Porter and E. B. Hook, eds. Academic, New York, pp. 261-288.

Watkins, P. J. 1982. Congenital malformations and blood glucose control in diabetic pregnancy. $\mathrm{Br}$. Med. J. 1:1357-1358.

Weiner, M., and Friedlander, R. L. 1971. Abnormal progesterone synthesis in placental tissue from a spontaneous abortion. Am. J. Obstet. Gynecol. 111:942-946.

WHO 1977. Non-mendelian developmental defects: Animal models and implications for research into human disease. Bull. World Health Org. 55:475-487.

Wingate, M. B. 1968. Anatomic studies on midtrimester abortions. Am. J. Obstet. Gynecol. 102:901902.

Zulman, J. J., Talal, N., Hoffman, G. S., and Epstein, W. V. 1980. Problems associated with the management of pregnancies in patients with systemic lupus erythematosus. J. Rheumatol. 7:3749. 